\title{
Size-segregated particulate matter inside residences of elderly in the Metropolitan Area of São Paulo, Brazil
}

\author{
Bruna Segalin $^{\text {a, b }}$, Prashant Kumar ${ }^{\text {b, c, } 1 \text {, Kaonan Micadei }}{ }^{\text {, }}$, Adalgiza Fornaro ${ }^{\text {a }}$ Fabio L. \\ T. Gonçalves ${ }^{\mathrm{a}}$
}

${ }^{a}$ Departamento de Ciências Atmosféricas, Instituto de Astronomia, Geofísica e Ciências Atmosféricas, Universidade de São Paulo, Rua do Matão, 1226, 05508-090, São Paulo - São Paulo, Brasil

${ }^{\mathrm{b}}$ Department of Civil and Environmental Engineering, Faculty of Engineering and Physical Sciences, University of Surrey, Guildford GU2 7XH, United Kingdom

${ }^{\mathrm{c}}$ Environmental Flow (EnFlo) Research Centre, Faculty of Engineering and Physical Sciences, University of Surrey, Guildford GU2 7XH, United Kingdom

${ }^{\mathrm{d}}$ Centro de Ciências Naturais e Humanas, Universidade Federal do ABC, Avenida dos Estados, 5001, 09210-580, Santo André-São Paulo, Brasil

\footnotetext{
${ }^{1}$ Corresponding author. Address as above. Tel.: +44 1483 682762; Fax: +44 1483 682135; Email addresses: P.Kumar@surrey.ac.uk, Prashant.Kumar@cantab.net
} 


\section{Graphical abstract}

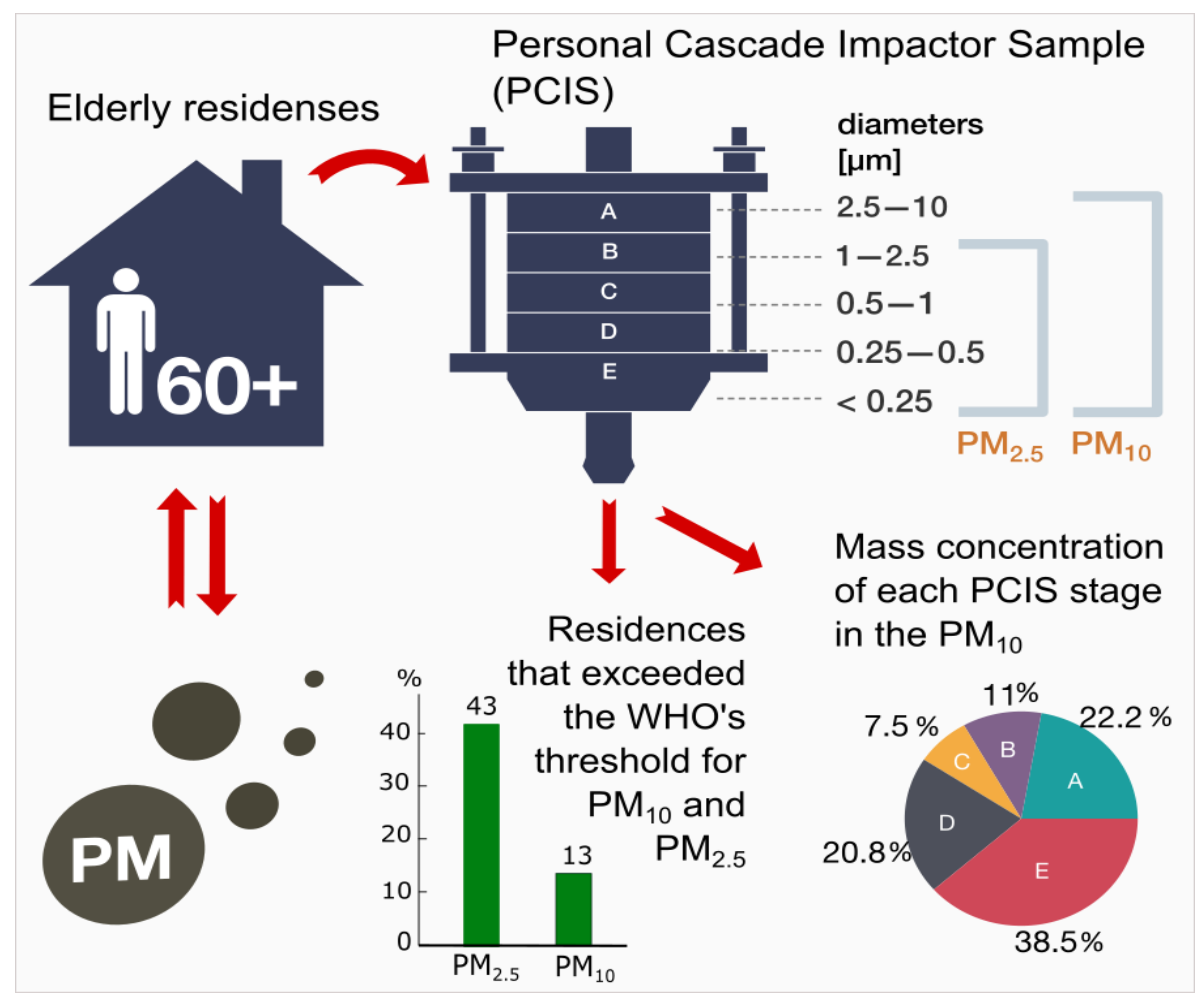

\section{Abstract}

The elderly population spend relatively more time indoors and is more sensitive to air pollution-related health risks but there is limited information on the quality of the air they breathe inside their residences. The objectives of this work are to (i) characterise mass of size-segregated particulate matter (PM) in elderly residences in Metropolitan Area of Sao Paulo (MASP) in Brazil, (ii) assess the impact of the meteorological parameters on the behaviour of indoor PM concentrations, (iii) evaluate the indoor and outdoor relationship of PM mass concentration, and (iv) estimate the respiratory deposition doses (RDD). To achieve these objectives, we measured mass concentrations of size-segregated particles in 59 elderly residences in MASP. The measurements were made in the $0.25-10 \mu \mathrm{m}$ size range in 5 size bins using a Personal Cascade Impactor Sampler. We evaluated the mass concentration of 
particles using a gravimetric method and compared our $\mathrm{PM}_{10}$ (sum of all size bins) and $\mathrm{PM}_{2.5}$ (sum of all size bins, except $\mathrm{PM}_{10-2.5}$ ) concentrations against the $24 \mathrm{~h}$ mean guidelines recommended by World Health Organization (WHO). Our results show the mean $\mathrm{PM}_{10}$ and $\mathrm{PM}_{2.5}$ measured in elderly residences in MASP as 35.2 and $27.4 \mu \mathrm{g} \mathrm{m}^{-3}$, respectively. $\mathrm{PM}_{2.5}$ and $\mathrm{PM}_{<0.25}$ (particles with aerodynamic diameter of less than $0.25 \mu \mathrm{m}$ ) contributed $78 \%$ and $38 \%$ of total $\mathrm{PM}_{10}$, respectively, clearly suggesting a significantly high exposure to fine particles by the elderly. About 13 and $43 \%$ of the measurements exceeded the WHO's $\mathrm{PM}_{10}$ and $\mathrm{PM}_{2.5}$ guidelines, respectively. The samples were clustered into five groups to found the behaviour of indoor PM. The cluster representing the residences with higher PM concentration in all size bins are predominantly residences near the heavy traffic areas during the non-precipitation days. About $68 \%$ of residences showed the highest fraction of $\mathrm{PM}_{<0.25}$, indicating a high concentration of ultrafine particles in these residences. We calculated indoor/outdoor $(I / O)$ rates and found them as 1.89 and 1.06 for $\mathrm{PM}_{2.5}$ and $\mathrm{PM}_{10}$, respectively. About $77 \%$ and $40 \%$ of the residences had higher $\mathrm{PM}_{2.5}$ and $\mathrm{PM}_{10}$ indoors than those in outdoor environments. During seated position, the RDD rates for coarse and fine particles for male elderly were found to be about $20 \%$ and $25 \%$ higher compared with female elderly, respectively. Our findings suggest a control of indoor sources in the elderly residences to limit adverse health effects of particulate matter, especially fine particles, on elderly.

Keywords: Size-segregated particulate matter; Elderly residences; Indoor air quality; Urban area of São Paulo; Indoor/outdoor ratio; Respiratory deposition

\section{List of abbreviations}

CETESB - Company Environmental State of São Paulo

$D F$ - Deposition Fraction

$I / O$ - Ratio between indoor and outdoor particulate matter concentrations 
MASP - Metropolitan Area of São Paulo

PCIS - Personal Cascade Impactor Sampler

PM - Particulate Matter

rBC - Black carbon measured by reflectance

RDD - respiratory deposition doses

RH - Relative Humidity

WHO - World Health Organization

\section{Introduction}

The air pollution is known to have a range of adverse effects on human health in the form of, for example, renal, cognitive, respiratory and cardiovascular diseases (Kampa and Castanas, 2008; Brook, 2008; Power et al., 2011; Arbex et al., 2012; Weuve et al., 2012; Mehta et al., 2016). Among all the pollutants, the particulate matter (PM) is the one with the greatest health impact on the human health (WHO, 2006) and therefore is the focus of this study. The inhalable fraction of $\mathrm{PM}$, which is $\mathrm{PM}_{10}$, can be divided into coarse $\left(\mathrm{PM}_{2.5-10}\right)$ and fine particles $\left(\mathrm{PM}_{2.5}\right)$. The fine particles also contain particles below $100 \mathrm{~nm}$, which are referred to as ultrafine particles, $\mathrm{PM}_{0.1}$ (Kumar et al., 2014; Seinfeld and Pandis, 2016). The ultrafine particles are known to have much greater health impacts than their larger counterparts (Martins et al, 2010; Kumar et al., 2011). The fine particles reach the alveoli while ultrafine particles can translocate from respiratory epithelium towards circulation and reach organs such as heart and brain and cause adverse effects (Elder et al., 2006; Heal et al., 2012).

The susceptibility to air pollution varies with different age groups, socioeconomic status, and pre-existing health conditions (Pope, 2000; Peled, 2011; Olmo, 2011). The elderly among the other population groups are ageing faster worldwide, especially in the MASP (Alessandri and Maeda, 2011; United Nations, 2015). The air quality standards for $\mathrm{PM}_{2.5}$ or $\mathrm{PM}_{10}$ may not be 
safe for elderly people and even exposure to much lesser concentrations, compared with the younger age groups, could lead to much higher health risks in elderly because of their lower immunity and less efficient respiratory system (Saldiva et al., 1995; Gouveia and Fletcher, 2000; Peled, 2011; Olmo et al., 2011; Arbex et al., 2012). For example, past studies suggest association of PM and its compounds with health problems in the elderly such as the acute respiratory inflammation, pneumonia, asthma chronic obstructive pulmonary disease, autonomic cardiac dysfunction, renal and cognitive deficit, and cardiovascular and respiratory mortality (Saldiva et al., 1995; Liao et al., 1999; Simoni et al., 2003; Holguín et al., 2003; Gonçalves et al., 2007; Halonen et al., 2009; Power et al., 2011; Nascimento, 2011; Weuve et al., 2012; Han et al., 2016; Mehta et al., 2016).

In Metropolitan Area of São Paulo (MASP), an ever increasing rate of air pollution due to road vehicles and industries pose significant health risks compared with its surrounding suburban areas (Kumar et al., 2016). For example, outdoor $\mathrm{PM}_{2.5}$ was found to be associated with 10,000 deaths per year in the MASP (Miranda et al., 2012). However, there is no parallel information about the effects of indoor PM on public health, especially the elderly. This aspect is therefore taken for investigation in this work.

There are uncertainties about the health risk estimates associated with exposure to indoor PM (Lianou et al, 2007) since most of the epidemiological studies are focused on outdoor particles. The urban inhabitants spend up to $90 \%$ of their time indoors at home, work or elsewhere (Brown, 1997; Klepeis et al., 2001). Moreover, the concentrations of different PM types vary depending on the type of indoor environments and the quality of the outdoor air surrounding them (Kumar and Morawska, 2013; Salthammer et al., 2016). There is a need to characterise the PM concentrations in indoor environments such as the elderly residence that are considered for assessment as part of this work. 
The recent estimates suggest an increase in the number of elderly worldwide from $12.3 \%$ in 2015 to $21.5 \%$ in 2050 (United Nations, 2015). In particular, Brazil is the $5^{\text {th }}$ most populous country in the world and almost $30 \%$ of its population is expected to cross 60 years, and $6.7 \%$ over 80 years, by 2050 (United Nations, 2015). Past research in Italy has reported that the elderly people spent significantly more time at home than the other age groups, mainly due to reduced outdoor activities and thereby get exposed to harmful indoor air pollutants for more time (Simoni et al., 2003). For this reason, measurements in such residences are extremely important to assess their air quality. While the toxicological and epidemiological studies present evidence of health effects for PM mass concentration (Elder et al., 2006; Kampa and Castanas, 2008; Brook, 2008; Arbex et al., 2012; Heal et al., 2012; Power et al., 2011; Nascimento, 2011; Olmo, 2011; Weuve et al., 2012; Han et al., 2016; Mehta et al., 2016), the effects of different particle sizes on human health still require exhaustive assessments. The knowledge of their exposure doses is, therefore, important and is also covered within the scope of this present work.

As summarized in Table 1, there are limited studies worldwide that focus on the size-resolved particles in indoor environments and most of the focus usually remains on $\mathrm{PM}_{10}$ and $\mathrm{PM}_{2.5}$ (Chao and Wong, 2002; McCormack et al., 2008) or include $\mathrm{PM}_{1}$ at the maximum (Jones et al., 2000; Goyal and Kumar, 2013; Viana et al., 2014). Studies for indoor elderly environments focusing on size-segregated particles are yet limited. For example, Holguín et al. (2003) measured $\mathrm{PM}_{2.5}$ mass concentration for $24 \mathrm{~h}$ in an asylum in Mexico. They reported that $\mathrm{PM}_{2.5}$ can interfere with the cardiac frequency of the elderly. Osman et al. (2007) measured $\mathrm{PM}_{2.5}$ mass concentration for about $14 \mathrm{~h}$ in residences in North East Scotland. They discovered higher levels of association of $\mathrm{PM}_{2.5}$ with the worst chronic obstructive pulmonary disease in these elderly. However, the analysis of the different size of PM in the elderly 
residential environments, covering a full $24 \mathrm{~h}$ diurnal cycle, has not studied in the past studies. In the best of our knowledge, this is the first study in Latin America that focuses on understanding the size-resolved particles and their exposure doses in the elderly residences. We carried out comprehensive measurements in 59 elderly residences to (i) quantify sizesegregated PM mass concentration in indoor air of these residences, (ii) assess the influence of outdoor meteorological conditions on the indoor PM concentration, (iii) understand the relationship between the indoor and outdoor $(I / O) \mathrm{PM}$ mass concentrations, and (iv) estimate the respiratory deposition doses (RDD) of the size-segregated particles.

\section{Methodology}

\subsection{Site description}

The MASP is situated in the State of São Paulo in Brazil (Figures 1a-b). The MASP has a population of about 21 million and is the $12^{\text {th }}$ major agglomeration of the world (IBGE, 2016; City Population, 2016). This agglomeration includes the city of São Paulo with almost 12 million people (IBGE, 2016). The pollution levels in the MASP are amplified by weather conditions (e.g., thermal inversion, light winds, little precipitation and high levels of solar radiation) that inhibit the dispersion of pollutants during the winter season between June and September (CETESB, 2016).

The fixed-site air quality monitoring in MASP is made by automatic monitoring network, run by the Company Environmental State of São Paulo (CETESB). The CETESB is a governmental organization, responsible for certifying the quality of air and water in São Paulo. About $87 \%$ of the air pollution monitored in the city of São Paulo comes from more than 8.2 million vehicles (CETESB, 2015; DETRAN, 2016). A number of interventions have already been taken to reduce the pollutant concentrations in the MASP but the outdoor levels of PM concentrations still remain over the local standards during most of the time (Kumar et 
al., 2016).

More than $12 \%$ of people living in the city of São Paulo are 60 or more years older; this percentage is growing year after year (Alessandri and Maeda, 2011). In this study, the people are considered as elderly when they cross 60 years of age. We had 60 elderly volunteer who participated in our work (Section 2.2); none of them were nursing home dwellers. The most part of the elderly population in Brazil lives in their own or relatives residences. For example, more than $64 \%$ of the elderly are responsible to financially support their residences in the Brazilian familiar structure (IBGE, 2000). Moreover, the nursing of elderly is through private care that is very expensive and affordable only by very few elderly while the majority of financially deprived or homeless elderly live in adverse conditions (Quiroga, 2007). Both of these categories of elderly did not meet our volunteer selection criteria (Section 2.2). Activities by the residents inside their residences contribute to increased concentration of pollutants indoor (Ferro et al., 2004). In addition, the elderly population does not open their windows often. In this way, the environmental exposure in elderly residences differs from the other age groups because the elderly spend most of their time inside their residences (Section 2.2) while the other age groups spend much of their daytime away from their residences (e.g., children staying in school and adults at the work).

Figure 1c shows the location of elderly residences in the MASP. A total of 60 samples were collected from 59 elderly residences. These samples were collected from the cities of São Paulo (57), Osasco (2) and Embu das Artes (1), all belonging to MASP. The sampled areas cover more than $62 \%$ of the population of the MASP, which has the highest proportion of elderly compared with the rest of the city (Alessandri and Maeda, 2011; IBGE, 2016). Therefore, our study region represents the area with the highest density of the elderly. Out of the total 59 residences studied, 37 were apartments whereas 22 were detached houses; most of 
this residences were a single story built at the ground-level. All these residences were naturally ventilated where the wind and buoyancy-induced flow transported the outdoor pollutants to indoors through open windows and doors. In São Paulo, only a few richest people have central heating or cooling system and less than $2 \%$ of the population have air conditioning in their residences (IBGE, 2004). All the MASP residences use liquefied petroleum gas in individual cylinders or piped natural gas for cooking purposes. The residences use electricity, mainly hydroelectricity, for heating as well as hot water for shower.

\subsection{Study design}

This study was carried out within the framework of FAPESP funded project (2010 / 10189-5), which intends to quantify the effects of environmental parameters (weather, thermal comfort), air pollution and climate change on the geriatric population of São Paulo. Within the framework of this project, we selected volunteers from the Faculty of Medicine Clinics Hospital at the University of São Paulo, as per the criteria pre-established by the project team of geriatricians. The main criteria were that the person had to be either 60 years of age or older and should be a volunteer accepting the terms of consent, approved by the Ethics Committee in Research of the Faculty of Medicine Clinics Hospital at the University of São Paulo (number 619274). Among the criteria, the elderly should have four years or more of schooling. They should not be obsessed, depressed, or disabled (on wheelchairs or crutches). Only the elderly that passed all these conditions were selected to participate as our volunteers. Thus, the studied residences chosen were those where the approved volunteers live.

Initially, we had 88 elderly volunteers. Of which, 11 did not pass in at least one of our criteria and another 14 dropped out due to their sick health. This left 63 elderly houses for our measurements; 3 of them had an error in data set leaving a legitimate data set of 60 elderly. We placed Personal Cascade Impactor Sampler (PCIS) for the collection of size-segregated 
samples in the living rooms of 60 elderly for 24 hours in each case (Section 2.3). We collected 60 samples from 59 elderly residences because two volunteers were living in the same residence. Out of 59 elderly residences, six of these residences have a smoker resident (Table 2). There were 47 female and 13 male volunteers in our 60 elderly; this proportion was expected given that the MASP has relatively more female than male elderly (30\%; Alessandri and Maeda, 2011). These 60 elderly stayed $79 \%(19.0 \pm 2.2 \mathrm{~h})$ of total $24 \mathrm{~h}$ of time inside their residences, which is up to $\sim 13 \%$ higher time than the elderly studied in Italy (Simoni et al., 2003). These elderly are $73.9 \pm 5.7$ years old and the oldest is a female 87 years old.

\subsection{Instrumentation}

We sampled the PM data with the PCIS, which is a miniaturised cascade impactor. It has the following four impaction and one post-filter stages: 10-2.5 $\mu \mathrm{m}$ (referred hereafter as A), $2.5-1.0 \mu \mathrm{m}(\mathrm{B}), 1.0-0.5 \mu \mathrm{m}(\mathrm{C}), 0.5-0.25 \mu \mathrm{m}(\mathrm{D})$ and $<0.25 \mu \mathrm{m}$ (E; this is a post-filter stage and referred interchangeably as $\left.\mathrm{PM}_{<0.25}\right)$. The schematic diagram of the PCIS can be seen in Supplementary Information (SI), Figure S1 and its further description can be found elsewhere (Misra et al., 2002; Sioutas, 2004). To ensure that the particles are separated precisely in these size-bins, the PCIS must be used with a Leland Legacy Sample Pump (SKC Inc., Cat. No. 100-3000), which runs at a sample flow rate of $9 \mathrm{~L} \mathrm{~min}^{-1}$. The PCIS is optimised for this flow rate for $24 \mathrm{~h}$ (Sioutas, 2004). The particles were collected on a $25 \mathrm{~mm}$ Teflon filter above the cut-off points for A, B, C and D. In order to gather $\mathrm{PM}_{<0.25}(\mathrm{E})$, the PCIS used a $37 \mathrm{~mm}$ Teflon filter (SI Figure S2). Teflon is preferred for collecting such particles since this does not interfere with gravimetric analysis and chemical composition (Misra et al., 2002).

Past validation tests have shown that PCIS can collect up to $3.6 \mathrm{mg}$ of fine particles and 0.7 of coarse particles (Sioutas, 2004) and that there is no efficiency loss in the measurement of PM 
up to $10 \mu \mathrm{m}$ in environments that have the wind speed up to $2.2 \mathrm{~m} \mathrm{~s}^{-1}$ (Singh et al., 2003). The PCIS is small and lightweight and can be hung on a person's clothing collar (SI Figure S1). However, the elderly found inconvenient to carry both the PCIS and the pump due to noise and weight of the pump. For this reason, we placed the PCIS inside their living rooms, where elderly people spend the majority of their daily time, at a height of between 0.5 and 1.0 m. Since elderly spend $79 \%$ of their total daily time in their residences, our measurements can be considered representative of their indoor exposure.

In order to circumvent contamination and maintain the quality assurance and precision of our measurements, we made an ultrasonic cleaning in the PCIS before each measurement to avoid contamination of samples from one residence to another. We calibrated the pump before each measurement to avoid variations in the flux with the time of continued use. We also evaluated blank filters (without sample) for all the handling processes and measurement to assess any sign of contamination.

\subsection{Data collection and analysis}

The samples were collected between a period of May 2014 and July 2015, as per the availability of the elderly volunteers. The samples were collected in March (5), April (6), May (9), June (13), July (15), September (1), October (6), November (4) and December (1). A total of 31 samples were collected in 2014 and the rest of the 29 samples in 2015 . In each case, the sampling started during the morning in different hours in accordance with the availability of the elderly, continuously for $24 \mathrm{~h}$ in each residence, except for one residence where two elderly were volunteers; we made two measurements on two different dates in this residence. The PM mass concentrations collected on the samples were weighed using a gravimetric method that had a precision scale of $1 \mu \mathrm{g}$ (MX5; Mettler-Toledo, Columbus, OH, USA). These weights were taken in a room with controlled environmental conditions that had a 
temperature of $22 \pm 2^{\circ} \mathrm{C}$ and relative humidity $(\mathrm{RH})$ of $45 \pm 3 \%$. For obtaining the $\mathrm{PM}_{10}$ and $\mathrm{PM}_{2.5}$ mass concentration, we sum the mass concentration of impaction stages $\mathrm{A}-\mathrm{E}$ and $\mathrm{B}-\mathrm{E}$, respectively (Section 2.3).

In order to understand the behaviour of size-segregated PM mass concentration in elderly residences, we carried out a cluster analysis by grouping our data. The cluster analysis is used to group a set of data; for example, the data with similarity patterns stay in the same group and referred as a cluster (Wilks, 1995; Maimon and Rokach, 2010). We put the elderly residences with a similar profile of size-segregated PM in one of the clusters by using the R package "Cluster", which is an open-source statistical tool, for partitioning (clustering) our data into 5 clusters (Kaufman and Rousseeuw, 1990). We apply this partitioning method in 59 residences. The residence \#27 is not added in this analysis due to being an outlier with a significant higher PM mass concentration (Section 3.1); otherwise, this could have added far greater weight in the cluster and falsify the representativeness of the groups.

We also calculated the shortest distance between each of the 60 sampled residences and the 27 fixed-site outdoor official air quality monitoring stations (run by the CETESB) in the MASP to find out the closest station to the sampled residences and compare them with the measured indoor concentrations on the same date. The atmospheric concentrations of $\mathrm{PM}_{2.5}$ and $\mathrm{PM}_{10}$ from CETESB were obtained by beta continuous ambient particulate monitors (Thermo Scientific 5014i, Electron Corporation, USA).

\subsection{Estimation of exposure doses}

We calculated the total respiratory deposition doses (RDD) in the respiratory tract of elderly using the Eq. (1), as used by earlier studies (Azarmi and Kumar, 2016; Kumar and Goel, 2016): 


$$
R D D=(V T \times f) \times D F i \times P M i
$$

where $V T$ is a tidal volume $\left(\mathrm{m}^{3}\right.$ per breath), $f$ is the typical breath frequency (breath per minute), $D F i$ is deposition fraction of a size fraction $i$, and $\mathrm{PM}_{\mathrm{i}}$ is the mass concentration in different size fractions. The DF is estimated using the Eq. (2), given by (Hinds, 1999), as:

$$
D F=\operatorname{IF}\left(0.0587+\frac{0.911}{1+\exp \left(4.77+1.485 \ln d_{p}\right)}+\frac{0.943}{1+\exp \left(0.508-2.58 \ln d_{p}\right)}\right)
$$

where $d_{\mathrm{P}}$ is the mean diameter and $I F$ is given by Eq. (3), given by (Hinds, 1999), as:

$$
I F=1-0.5\left(1-\frac{1}{1+0.00076 d_{p}^{2.8}}\right)
$$

The values of $V T$ and $f$ depend on the person gender and physical activity (Hinds, 1999). Considering elderly in an indoor environment, we chose light exercise and seated positions as their physical activities. For light exercise, $V T$ and $f$ values are taken as $9.9 \times 10^{-4}\left(12.5 \times 10^{-4}\right)$ $\mathrm{m}^{3}$ per breath and 21 (20) breath per minute for female (male), respectively (Hinds, 1999). For seated position, 国 and are taken as $4.6 \times 10^{-4}\left(7.5 \times 10^{-4}\right) \mathrm{m}^{3}$ per breath and 14 (12) breath per minute for female (male), respectively (Hinds, 1999).

\section{Results and Discussion}

\subsection{Size-segregated PM mass concentration}

Figure 2 shows the mass concentration of $\mathrm{PM}_{10}$ and $\mathrm{PM}_{2.5}$ in elderly residences and the percentage in each of the PCIS stages present in $\mathrm{PM}_{10}$ (Figure 2a) and $\mathrm{PM}_{2.5}$ (Figure 2b). Fine particles were found to dominate $(77.8 \%)$ of total $\mathrm{PM}_{10}$ mass concentrations inside the elderly residences, leaving a difference of $22.2 \%$ for coarse particles (see A in the pie graph, Figure 2a without the sample \#27). The fraction of fine particles inside the elderly residences is much higher $(\sim 18 \%)$ than those in the outdoor environment of the MASP where $\mathrm{PM}_{2.5}$ contribution to $\mathrm{PM}_{10}$ is $\sim 60 \%$ (CETESB, 2015). On the other hand, the $\mathrm{PM}_{<0.25}$ is a dominant fraction of fine particles, contributing up to about $50 \%$ of $\mathrm{PM}_{2.5}$ (Segalin et al., 2016), suggesting their 
origin from fuel burn by vehicles. Results of our previous work showed that the black carbon measured by reflectance (rBC; tracer of fuel combustion) was more than $26 \%$ of the $\mathrm{PM}_{<0.25}$ measured in these elderly residences. These results indicate a significant contribution from vehicular emissions inside our studied residences due to the majority of them being close to streets with intense road traffic (Segalin et al., 2016).

The distribution of PM in elderly residences is asymmetric, except for $\mathrm{PM}_{0.5-1.0}$, with a greater variability in $\mathrm{PM}_{<0.25}$ (Figure 3a). For example, our mean $\mathrm{PM}_{10}$ and $\mathrm{PM}_{2.5}$ were found to be 35.2 and $27.4 \mu \mathrm{g} \mathrm{m}^{-3}$, respectively (Table 2). The mean mass concentration of $\mathrm{PM}_{<0.25}$ was found to be $13.6 \mu \mathrm{g} \mathrm{m}^{-3}$, which is 1.7-times higher than the coarse particles $\left(\mathrm{PM}_{2.5-10}\right.$; Table 2). Comparisons with the literature indicate our mean $\mathrm{PM}_{2.5}\left(27.4 \mu \mathrm{g} \mathrm{m}{ }^{-3}\right)$ to be lower than those found in an indoor asylum in City of Mexican (35.1 $\mu \mathrm{g} \mathrm{m}^{-3}$; Holguín et al., 2003). Since the asylum building was smoke-free, Holguín et al. (2003) speculated that the high $\mathrm{PM}_{2.5}$ mass concentration come from diesel buses that were parked close to the asylum. Likewise, the mean $\mathrm{PM}_{10}$ and $\mathrm{PM}_{2.5}$ in our studied elderly residences were also found to be lower than those in indoor children residences (Table 1; McCormack et al., 2008), mainly due to cooking and more frequent smoking than those in elderly residence. Our $\mathrm{PM}_{<0.25}$ mass concentration was similar to those found in indoor schools (Viana et al., 2014), as summarised in Table 1. The smoking-free environment in both these studies was a similarity that might have made our results comparable but we could not find any other specific reason behind this coincidental similarity.

The pie graph in Figure 2 shows the percentage of each PCIS stage in $\mathrm{PM}_{10}$ and $\mathrm{PM}_{2.5}$, with and without the sample \#27. There is a significant difference in mean concentrations when we considered sample \#27 (see pie graph with sample \#27 in Figures $2 \mathrm{a}$ and $2 \mathrm{~b}$ ). This sample is highlighted in Figure $3 \mathrm{~b}$ due to its highest mass concentration to $\mathrm{PM}_{10}, \mathrm{PM}_{2.5}$ (highlighted in 
red colour in Figures $2 \mathrm{a}$ and $2 \mathrm{~b}$ ) and $\mathrm{PM}_{<0.25}$ (Figure $3 \mathrm{~b}$ ) that changes the overall mean of proportions, mean and standard deviation of mass concentration significantly (Table 2). For example, almost $90 \%$ of contribution for $\mathrm{PM}_{10}$ in sample \#27 came from $\mathrm{PM}_{<0.25}$ and $8 \%$ from $\mathrm{PM}_{0.5-0.25}$ (Figure 3b). The mean difference between mean mass concentration for all fractions of PM, with and without sample \#27, was higher for the fine particles, especially $\mathrm{PM}_{<0.25}$. The sample \#27 increased $23.7 \%$ in $\mathrm{PM}_{<0.25}$ mean mass concentration but showed a little influence on the mean of coarse particles and $\mathrm{PM}_{1.0-2.5}$.

The highest concentrations in sample \#27 point to an interesting source. This residence was next to a construction site where the construction activities were active during the measurement period, indicating an escape of particles from this site and infiltrating from outdoor to indoor in this residence through openings of doors (and windows) during their movement in and out from the home. These results also show that the mass concentration of fine and coarse particles from the construction can appreciably change. Azarmi et al. (2016) found that $\mathrm{PM}_{10}$ and $\mathrm{PM}_{2.5}$ in constructions can be until $120 \%$ and $11 \%$ higher during the work than no work, respectively. They showed that $\mathrm{PM}_{10}$ and $\mathrm{PM}_{2.5}$ mass concentration decreased with the increase of the distance of the emission from construction and, in a few $100 \mathrm{~m}$ the mass concentration can be half of its value. However, the residence \#27 was about 50 m away from the construction, what can explain the high mass concentration inside the residence. The differences between indoor coarse and fine particles (Figure 3b) could be due to the much faster exponential decay rate of $\mathrm{PM}_{10}$ compared with $\mathrm{PM}_{2.5}$ (Azarmi et al., 2016). Furthermore, windows were closed during the construction inhibiting the penetration of coarse particles, but very fine particles $\left(\mathrm{PM}_{<0.25}\right)$ could still infiltrate indoors through the residential shells such as cracks and fissures (Abt et al., 2000). The effects of traffic influence in sample \#27, compared with the rest of the samples, can be disregarded because of the 
lowest proportion of $\mathrm{rBC}$ (i.e., $0.9 \%$ of the $\mathrm{PM}_{<0.25}$ mass) being found in this sample (Segalin et al., 2016). We also investigated the influence of cigarette smoking in indoor elderly residences since such a smoke can contribute notably to very fine particles (e.g., $\mathrm{PM}_{<0.25}$ ) than residences without a smoker (Table 2). We have about $10 \%$ residence with a smoker during the measurement (Table 2). However, there were no smokers during the measurements of sample \#27, eliminating the effect of smoking as a reason for high $\mathrm{PM}_{<0.25}$.

We used both the CETESB (2015) and the WHO (2010) guideline values (shown by two different lines in Figure 2) for comparison with our daily averaged data inside the elderly residences. The CETESB standard values (daily mean $\mathrm{PM}_{10}$ and $\mathrm{PM}_{2.5}$ as 120 and $60 \mu \mathrm{g} \mathrm{m}^{-3}$, respectively) are higher than $\mathrm{WHO}$ guidelines (daily mean $\mathrm{PM}_{10}$ and $\mathrm{PM}_{2.5}$ as 50 and $25 \mu \mathrm{g}$ $\mathrm{m}^{-3}$, respectively) since CETESB intends to adopt the WHO guidelines over the time in future (Kumar et al., 2016). Only one residence exceeded the CETESB's standards (the aforementioned sample \#27) whereas $13 \%$ and $43 \%$ of the residences exceeded the WHO's $\mathrm{PM}_{10}$ and $\mathrm{PM}_{2.5}$ guidelines, respectively. In fact, the $\mathrm{PM}_{<0.25}$ fraction itself exceeded the WHO's $\mathrm{PM}_{2.5}$ guidelines on $11.7 \%$ of the total occasions in the elderly residences (Segalin et al., 2016), showing the significantly high mass concentration of finer sized particles. The highest values of $\mathrm{PM}_{10}$, without the residence \#27 (Figure 3b), were 70.2, 69.6 and $68.2 \mu \mathrm{g} \mathrm{m}^{-}$ ${ }^{3}$; these are up to about $20 \mu \mathrm{g} \mathrm{m}^{-3}$ above the WHO's guidelines. Likewise, the highest values of $\mathrm{PM}_{2.5}$ were $59.5,55.8$ and $51.8 \mu \mathrm{g} \mathrm{m}^{-3}$; all of them exceeding by over two-times the daily WHO guideline of $25 \mu \mathrm{g} \mathrm{m}^{-3}$. The above results allow concluding that the elderly in the MASP have disproportionately high concentrations of fine particles in their residences, where they spend almost $80 \%$ of their total daily time (Section 2.2).

\subsection{Influence of outdoor meteorological conditions on the indoor PM concentration}

In order to understand the PM mass concentration behaviour in elderly residences, we 
clustered our samples into five groups (Figure 4). These clusters were chosen because they represent better the different PM behaviours seen in the residences. The cluster 1 represents the residences $(13.6 \%)$ with a higher concentration of PM in all sizes. These are residences near to intense vehicular traffic and these samples were collected in days without a precipitation. The cluster 2 represents the measurements made during the precipitation events. This cluster had the minimum mass concentration in all PCIS stages and describes the most part of the residences $(35.6 \%)$. All these measurements were made during the days when there was precipitation. The cluster 3 has the residences with more coarse particles (stage A) than the other PM sizes, mainly due to wind speed being higher during the measurements that would have favoured the resuspension of coarse particles (Harrison et al., 2001; Kumar et al., 2015). The cluster 4 has the same profile like as the cluster 1 , but with less mass concentration, whereas the cluster 5 has a different profile with the maximum concentrations in $\mathrm{PM}_{0.5-0.25}$ (stage D). All the clusters present low mass concentration in the $\mathrm{PM}_{0.5-1.0}$ (stage C). The major part of the residences $(67.8 \%)$ presents a peak of concentration in $\mathrm{PM}_{<0.25}$ (stage E), indicating much higher formation and infiltration of finer sized particles in elderly residences.

Figure 4 shows the behaviour of size-segregated PM in indoor elderly residences, indicating the highest values of $\mathrm{PM}_{<0.25}$; the same trend was also observed in outdoor urban environments. The highest concentration of outdoor $\mathrm{PM}_{<0.25}$ can be expected due to the contribution of elemental and organic carbon (Singh et al., 2003) and sulphates (Freitas and Solci, 2009), which are generated through combustion process and gas-to-particle conversion (Seinfeld and Pandis, 2016). Likewise, our $26 \%$ of indoor $\mathrm{PM}_{<0.25}$ was represented by rBC (Segalin et al., 2016) that consisted mainly the elemental carbon (Seinfeld and Pandis, 2016), explaining these highest concentrations in indoor elderly residences. 
Table 3 shows the mean meteorological parameter in each cluster (Figure 4), taken from the IAG station (Climatological Report, 2016), which had a mean distance of $13.9 \mathrm{~km}$ from the studied residences. All the measurements in cluster 1 , and about $64 \%$ of the residences in clusters 3 and 4, were sampled in winter (May-July). About 59\% of residences in cluster 2, and only $25 \%$ in cluster 5 , were sampled during this period. At this time of the year, the weather conditions are mostly dominated by the temperature inversions, neither wind nor precipitation, which are not favourable for dispersion of air pollutants (CETESB, 2015; CETESB, 2016). The cluster 2 represents the most part of samples in days with more strong precipitation than other clusters (Table 3, the most intense precipitation was in summer and spring. Usually, there are more intense events of precipitation in the MASP between November and March each year, which represents the rainy season (Liebmann et al., 2001; Climatological Report, 2016). Nevertheless, indoor $\mathrm{PM}_{10}$ and $\mathrm{PM}_{2.5}$ mass concentration in $13 \%$ and $43 \%$ of the elderly residences crossed WHO guidelines, respectively (Figure 2). The majority of these exceedances were noted during the months of July and October (SI Figure S3). In July, which represents a winter month, high-pressure weather system (i.e., anticyclones) caused thermal inversions in the lower atmosphere and reduced the wind speed (CETESB, 2015). In October, which represents a spring month, an atmospheric blocking caused by abnormal activity of subtropical anticyclone of the South Atlantic was observed on the MASP (CETESB, 2015). During both these months, the weather conditions were favourable to trap the PM close to the surface to result in increasing mass concentration in the region (Sánchez-Ccoyllo and Andrade, 2002).

We also assessed the difference in exceedances between 2014 and 2015. Almost 78\% and $70 \%$ of the $\mathrm{PM}_{10}$ and $\mathrm{PM}_{2.5}$ in elderly residences exceeded WHO guidelines in 2014, respectively (SI Figure S3). During the period from May to September of 2014 (covering the 
winter), there were 5\% additional days with unfavourable dispersion conditions higher than 2015 (CETESB, 2015; CETESB, 2016). This occurred mainly due to stable weather conditions during the winter that limited the dispersion of pollutants and hence increased the PM concentrations (Climatological Report, 2016; Sánchez-Ccoyllo and Andrade, 2002). Furthermore, there was relatively higher precipitation in June (14.4\%) and July (69.2\%) of 2015 compared with 2014 (Climatological Report, 2016), which might have also contributed to reduce the PM concentration in 2015. The higher PM concentration in the outdoor environment in 2014 might have resulted in increased indoor PM concentration when windows and doors are open or by infiltration through openings, and in turn leading to higher exceedances of indoor PM over the WHO guideline values in 2014 than those in 2015.

\subsection{Indoor and outdoor relationship}

The $I / O$ ratio is widely used since this provides a direct relationship between the PM mass concentrations in indoor and outdoor environments (Chen and Zhao, 2011). We calculated the distances between the residences and CETESB's station to find the closest station to each residence. After this, we take the $\mathrm{PM}_{10}$ (SI Tables S1) and $\mathrm{PM}_{2.5}$ (SI Tables S2) data from these stations to the same period of sampling in the residences with PCIS. The stations with less than 16 hours of valid diurnal measurements were excluded (CETESB, 2015). Due to this criterion, eight residences had their closest station with invalid data to the sampling period with PCIS, and therefore we used the second nearest station.

Figure 5a shows the indoor and outdoor $\mathrm{PM}_{10}$ mass concentration measured for all the 60 residences. About $40 \%$ of residences had the indoor $\mathrm{PM}_{10}$ higher than those outdoors. Among these residences, 6 had precipitation event during the sampling period. A possible explanation to high indoor $\mathrm{PM}_{10}$ compared with outdoors, may be due to the fact that the elderly closed the windows during the rain hours. The elderly residences have only natural ventilation and 
their $I / O$ mean is 1.06 (Figure $5 b$ ). Goyal and Kumar (2013) showed $I / O$ ratio for $\mathrm{PM}_{10}$ in kitchen and canteen with natural ventilation as 1.33 and 1.47 , respectively. In our elderly residences, the $I / O$ rate is lower, presumably because of the measurements being carried out in the living room with no direct sources of $\mathrm{PM}_{10}$ emissions. The highest $I / O$ was found for the sample \#27 due to the construction, as we discussed in Section 3.1. If we overlook the sample \#27 from the calculations, the $I / O$ becomes 0.99 , showing almost similar concentrations of indoor and outdoor $\mathrm{PM}_{10}$.

As for the $\mathrm{PM}_{2.5}$, about $77 \%$ of elderly residences have more $\mathrm{PM}_{2.5}$ mass concentration than the outdoors (Figure 6a). The $I / O$ for $\mathrm{PM}_{2.5}$ was found to be 1.89 , higher than the $\mathrm{PM}_{10}$, probably due to the effect of internal sources such as cooking and smoking on fine particles in the studied residences (Chao and Wong, 2002). These results also suggest that there are more production and/or penetration of fine particles inside the residences, coupled with greater deposition of coarse particles indoors compared with outdoors (Jones et al., 2000). The I/O ratio for $\mathrm{PM}_{2.5}$ presents 2 peaks at the samples \#27 and \#5 (Figure 6b). Chen and Zhao (2011) reported very high $I / O$ ratios for $\mathrm{PM}_{2.5}$ in the presence of indoor combustion sources and smoking; however, this was not the case in residences \#5 and \#27. The higher $I / O$ ratios for sample \#5 can be due to vehicular emissions since this residence was between two large avenues with intense road traffic (Av. Consolação and Av. Nove de Julho) where $21 \%$ of $\mathrm{PM}_{<0.25}$ was found to be rBC (Segalin et al., 2016). Therefore, the vehicular traffic seems to have made important influence to bring the observed differences in $\mathrm{PM}_{2.5}$ mass concentration. The residence \#27 had a high $I / O$ ratio for $\mathrm{PM}_{2.5}$ due to the construction work (Section 3.1) and the emissions from heavy construction machinery appear to have contributed to the observed difference (Azarmi et al., 2016; Azarmi and Kumar, 2016).

In order to understand the indoor/outdoor relationship between the mass concentration of 
$\mathrm{PM}_{10}$ and $\mathrm{PM}_{2.5}$, we established correlations in the form of Pearson and Spearman coefficients. The Pearson's coefficient evaluates the linearity between variables (Wilks, 1995) whereas the Spearman's coefficient evaluates an increase or decrease in one variable as a function of another variable (Wilks, 1995). As can be seen from SI Table S3, the Pearson's coefficient was low for both the $\mathrm{PM}_{10}$ and $\mathrm{PM}_{2.5}$. These relationships suggest that there is no linear relationship between indoor and outdoor PM. However, Spearman's coefficient is higher than Pearson's coefficient, suggesting that indoor mass concentration of PM can increase or decrease non-linearly with the outdoor PM mass concentration. This is possible since the sources of particles are usually different in indoor and outdoor environments (Jones et al., 2000). Likewise, the relationship between coarse and fine particles inside the elderly residences was found showing a low linear correlation $\left(R^{2}=0.39\right.$; SI Figure S4). The comparison of our results with the literature suggests the similar nonlinear relationship between coarse and fine particles, with a low $R^{2}$ value between $\mathrm{PM}_{2.5}$ and $\mathrm{PM}_{10-2.5}$ being $<0.30$ (Wilson and Shu, 1997). Such a correlation is expected due to the fact that the formation and removal processes of fine and coarse particles in the atmosphere are different (Heal et al., 2012; Seinfeld and Pandis, 2016).

\subsection{Respiratory deposition doses (RDD)}

The estimation of RDD for PM size-segregated is important to better understand the deposition of PM in the respiratory tract. We calculated the RDD for elderly male and female during a light exercise and a seated position (Figure 7). Elderly usually do not carry out heavy exercise in their residences and thereby justify our choice of physical activity. We found higher RDD in male than female for the same physical activity (Figure 7). This result was expected because male intakes larger tidal volume than females and hence inhale more PM (Hinds, 1999; Azarmi and Kumar, 2016; Section 2.5). This difference in intakes is because 
males have larger bodies than females; for example, the elderly males in our study were $10 \mathrm{~cm}$ taller and $5 \mathrm{~kg}$ heavier than the females.

The RDD is higher during the light activity than in seated position (Figure 7). It is because the light activity increases the frequency of breath and hence increases the deposition of PM in the respiratory tract (Hinds, 1999; Section 2.5). Table 4 shows the mean proportion of differences between RDD in male and female, using the RDD for males as a reference. The higher difference between RDD in male and female is in seated position. For example, fine particles RDD (sum of RDD in $\mathrm{PM}_{1.0-2.5}, \mathrm{PM}_{0.5-1.0}, \mathrm{PM}_{0.25-0.5}$ and $\mathrm{PM}_{<0.25}$ ) are $20 \%$ and $6 \%$ higher in males for seated and light exercise positions, respectively. The highest RDD difference was found in $\mathrm{PM}_{<0.25}$ which represented almost $29 \%$ and $17.2 \%$ higher deposition in males for seated and light exercise positions, respectively. This finding is concerning since these smaller particles show harmful effects on the human health compared with more coarse particles (Heal et al., 2012; Kumar et al., 2014; Han et al., 2016) and can favour deposition of endotoxin in pulmonary alveoli (Padhi et al., 2016).

Among the studied size bins, the largest RDD was found to be for the coarse particles $\left(\mathrm{PM}_{2.5-}\right.$ 10), followed by $\mathrm{PM}_{1.0-2.5}$ and $\mathrm{PM}_{<0.25}$ (Figure 7). We summed the RDD in all stages, except in $\mathrm{PM}_{2.5-10}$, in order to estimate the RDD to fine particles for comparison purposes (SI Table S4). The RDD for coarse particles were observed to be up to $5 \%$ and $10 \%$ higher than those for fine particles during both the light exercise and seated positions for female and male elderly, respectively (SI Table S4). However, when we calculated the RDD directly based on the $\mathrm{PM}_{2.5}$ mass concentration an opposite trend was seen, i.e., the RDD of fine particles was greater than those for coarse particles (Figure 8). This change occurred because the $D F$ is dependent on the mean particles diameter which was taken as $1.25 \mu \mathrm{m}$ for $\mathrm{PM}_{2.5}$, rather than the mean diameters taken as $1.75,0.75,0.38$ and $0.13 \mu \mathrm{m}$ for $\mathrm{PM}_{1.0-2.5}, \mathrm{PM}_{0.5-1.0}, \mathrm{PM}_{0.25-0.5}$ 
and $\mathrm{PM}_{<0.25}$, respectively, to estimate the $D F$. These results suggest that the knowledge of size-segregated diameter is necessary for estimating the accurate deposition fraction (Section 2.5) that has a direct influence on the RDD outcome.

\section{Summary and conclusions}

We measured the indoor mass concentration of size-segregated particles in the $0.25-$ $10 \mu \mathrm{m}$ size range in 5 size bins using a PCIS from 59 elderly residences in the MASP. The aims were to characterise size-segregated PM mass concentration in elderly residences, assess the impact of the meteorological parameters on the behaviour of indoor PM concentrations, evaluate the PM mass concentration indoor and outdoor relationship, and estimate the RDD. We evaluated the mass concentration of these particles by gravimetric method and compared to $\mathrm{PM}_{10}$ (sum of all sizes) and $\mathrm{PM}_{2.5}$ (sum of all sizes, except $\mathrm{PM}_{10-2.5}$ ) daily guidelines recommended by the WHO and CETESB. We clustered the samples into five groups in order to understand the PM indoor behaviour and evaluate the impact of the meteorological factors. We compared indoor measurements with outdoor measurements from fixed CETESB stations. We also calculated the PM deposition fraction in the respiratory tract for female and male elderly seated and light exercise positions.

Our results show that the mean value of measured $\mathrm{PM}_{10}$ and $\mathrm{PM}_{2.5}$ in elderly residences in MASP are 35.2 and $27.4 \mu \mathrm{g} \mathrm{m}^{-3}$, respectively. Both the $\mathrm{PM}_{10}$ and $\mathrm{PM}_{2.5}$ inside the elderly residences exceeded the WHO's guidelines in $13 \%$ and $43 \%$ of residences, respectively. About $78 \%$ of $\mathrm{PM}_{10}$ is composed by $\mathrm{PM}_{2.5}$ and $38.5 \%$ is composed by $\mathrm{PM}_{<0.25}$. These findings suggest that the elderly people in the MASP have disproportionately high concentrations of fine particles indoor where they spend almost $80 \%$ of their total daily time.

The majority of the residences $(67.8 \%)$ showed the maximum concentration in the $P M_{<0.25}$. This suggests that there is a significant production or infiltration of finer size particles in the 
majority of the elderly residences. The cluster analysis suggested increased concentrations of fine particles in the elderly residences, which were in the close proximity of the heavy road traffic during the days of no precipitation. The unfavourable (stable) weather conditions limiting the dispersion of $\mathrm{PM}$ and can favour the increase of the indoor $\mathrm{PM}_{10}$ and $\mathrm{PM}_{2.5}$. The effect of the construction site was evident on $\mathrm{PM}_{<0.25}$ mass concentration through a residence that was next to an active construction site. Smoking cigarettes is another factor that could have contributed to increased $\mathrm{PM}_{<0.25}$ mass concentration inside the elderly residences.

The $I / O$ ratio for $\mathrm{PM}_{10}$ was found to be $1.06 ; 40 \%$ of residences showed higher indoor $\mathrm{PM}_{10}$ than those outdoors. The $I / O$ for $\mathrm{PM}_{2.5}$ was found to be 1.89 ; about $77 \%$ of elderly residences showed higher indoor $\mathrm{PM}_{2.5}$ than those outdoors. This means that the production of fine particles indoor can be very high in the majority of the residences.

The RDD of all size-segregated PM were found to be higher for males than for females during the light exercise and seated positions, mainly because the respiratory rate is higher in male than female during both the physical activity conditions. The highest RDD was found to be higher for the coarse particles, followed by $\mathrm{PM}_{1.0-2.5}$ and $\mathrm{PM}_{<0.25}$. The sum of the RDD for fine particles, based on the size-segregated PM, was found to be lower than those for coarse particles during both activities. Although the coarse particles showed higher RDD the deposition rates the harmful effects are higher for the fine particles which were found in appreciable quantities.

The above findings suggest a necessity for routine indoor air quality monitoring and design targeted legislation and control measures to limit exposure to PM in different size ranges in the elderly residences of the MASP. Our findings also provide a solid basis for designing remediation actions for indoor PM concentrations in the elderly residences and consequently mitigate their adverse effect on human health. Such actions are important because the 
population is ageing faster in the MASP, and in general worldwide, and this population group is relatively more sensitive to air pollution impacts. Further studies on chemical analyses of size-segregated PM in elderly residences are recommended to assess the specific sources of PM in such residences. There is also need for the development of lighter and noiseless personal instruments than the PCIS, enabling personal exposure measurements of this fragile population for longer periods.

\section{Acknowledgements}

The authors thank the FAPESP for funding the project (2010 / 10189-5) - Human biometeorology: Analysis of the environmental variable effects (weather, thermal comfort and air pollution) and climate change in geriatric population of Sao Paulo - to the Department of Atmospheric Science, Institute of Astronomy, Geophysics and Atmospheric Science at the University of São Paulo (USP) for supporting this research program. We also thank CAPES (PROEX, Meteorology Post-Graduation Program at USP) and CNPq for the Bruna Segalin grants provided. Kaonan Micadei thanks the financial support from CAPES. We also thank the elderly volunteers and the Geriatric Department of Medicine Faculty at the USP, especially Dr. Alexandre Busse and Dr. Wilson Jacob Filho, for their help in accessing the residences of elderly volunteers. Prashant Kumar acknowledge the collaborative funding received to Universities of Surrey and São Paulo through the UGPN funded projects BIOBURN (Towards the Treatment of Aerosol Emissions from Biomass Burning in Chemical Transport Models through a case study in the Metropolitan Area of São Paulo) and NESTSEAS (Next-Generation Environmental Sensing for Local To Global Scale Health Impact Assessment) that assisted Bruna Segalin to work at the University of Surrey, United Kingdom.

\section{References}

Abt, E., Suh, H.H., Catalano, P., Koutrakis, P. (2000). Relative contribution of outdoor and 
indoor particle sources to indoor concentrations. Environmental Science \& Technology 34, 3579-3587.

Alessandri, M.R., Maeda, M.D. (2011) Informes Urbanos: Cresce o número de idosos. Prefeitura de São Paulo, Secretaria Municipal de Desenvolvimento Urbano de São Paulo. pp. 3. http://smdu.prefeitura.sp.gov.br/informes_urbanos/pdf/5.pdf (accessed 10 January 2016).

Arbex, M.A., Santos, U.D.P., Martins, L.C., Saldiva, P.H.N., Pereira, L.A.A., Braga, A.L.F. (2012). Air pollution and the respiratory system. Jornal Brasileiro de Pneumologia 38, $643-655$.

Azarmi, F., Kumar, P. (2016). Ambient exposure to coarse and fine particle emissions from building demolition. Atmospheric Environment 137, 62-79.

Azarmi, F., Kumar, P., Marsh, D., Fuller, G. (2016). Assessment of the long-term impacts of $\mathrm{PM}_{10}$ and $\mathrm{PM}_{2.5}$ particles from construction works on surrounding areas. Environmental Science: Processes \& Impacts 18, 208-221.

Brown, S.K. (1997) Indoor Air Quality. Department of Environment, Sport and Territories, State of Environment Technical Paper Series (Atmosphere). Canberra, Australia. ISBN: 0642252793. pp. 68.

Brook, R.D. (2008). Cardiovascular effects of air pollution. Clinical Science 115, 175-187.

CETESB (2015). Companhia Ambiental do Estado de São Paulo. Emissões veiculares no Estado de São Paulo. pp. 145. Available from: http://veicular.cetesb.sp.gov.br/relatorios-e-publicacoes/ (accessed 10 January 2016).

CETESB (2016). Companhia Ambiental do Estado de São Paulo. Relatório de qualidade do ar em São Paulo. pp. 167. http://ar.cetesb.sp.gov.br/publicacoes-relatorios/ (accessed 01 May 2016).

Chao, C.Y., Wong, K.K. (2002). Residential indoor $\mathrm{PM}_{10}$ and $\mathrm{PM}_{2.5}$ in Hong Kong and the elemental composition. Atmospheric Environment 36, 265-277.

Chen, C., Zhao, B. (2011). Review of relationship between indoor and outdoor particles: I/O ratio, infiltration factor and penetration factor. Atmospheric Environment 45, 275-288. 
City Population (2016). Population Statistics for Countries, Administrative Areas, Cities and Agglomerations. http://www.citypopulation.de/world/Agglomerations.html (accessed 28 June 2016).

Climatological Report (2016). Boletim Climatológico Anual da Estação Meteorológica do IAG/USP, Seção Técnica de Serviços Meteorológicos. Instituto de Astronomia, Geofísica e Ciências Atmosféricas da Universidade de São Paulo 18. pp. 76. ISSN: 1415-4374. http://www.estacao.iag.usp.br/boletim.php (accessed 06 July 2016).

DETRAN (2016). Departamento Estadual de Trânsito de São Paulo. Gabinete de planejamento $\mathrm{e}$ gestão. http://www.detran.sp.gov.br/wps/portal/portaldetran/detran/estatisticastransito/safrotaveiculos (accessed 10 June 2016).

Elder, A., Gelein, R., Silva, V., Feikert, T., Opanashuk, L., Carter, J., Potter, R., Maynard, A., Ito, Y., Finkelstein, J., Oberdörster, G. (2006). Translocation of inhaled ultrafine manganese oxide particles to the central nervous system. Environmental Health Perspectives 114, 1172-1178.

Ferro, A. R., Kopperud, R. J. Hildemann, L. M. (2004). Source strengths for indoor human activities that resuspend particulate matter. Environmental Science \& Technology 38, 1759-1764.

Freitas, A.D.M., Solci, M.C. (2009). Characterization of $\mathrm{PM}_{10}$ and $\mathrm{PM}_{2.5}$ and size distribution of chloride, nitrate and sulphate in urban and rural atmospheres of Londrina. Química Nova 32, 1750-1754.

Gonçalves, F.L., Braun, S., Dias, P.L.S., Sharovsky, R. (2007). Influences of the weather and air pollutants on cardiovascular disease in the metropolitan area of Sao Paulo. Environmental Research 104, 275-281.

Goyal, R., Kumar, P. (2013). Indoor-outdoor concentrations of particulate matter in nine microenvironments of a mix-use commercial building in megacity Delhi. Air Quality, Atmosphere \& Health 6, 747-757.

Gouveia, N., Fletcher, T. (2000). Time series analysis of air pollution and mortality: effects by cause, age and socioeconomic status. Journal of Epidemiology and Community 
Health 54, 750-755.

Halonen, J.I., Lanki, T., Yli-Tuomi, T., Tiittanen, P., Kulmala, M., Pekkanen, J. (2009). Particulate air pollution and acute cardiorespiratory hospital admissions and mortality among the elderly. Epidemiology 20, 143-153.

Han, Y., Zhu, T., Guan, T., Zhu, Y., Liu, J., Ji, Y., Gao, S., Wang, Fei., Lu, H., Huang, W. (2016). Association between size-segregated particles in ambient air and acute respiratory inflammation. Science of the Total Environment 565, 412-419.

Harrison, R.M., Yin, J., Mark, D., Stedman, J., Appleby, R.S., Booker, J., Moorcroft, S. (2001). Studies of the coarse particle $(2.5-10 \mu \mathrm{m})$ component in UK urban atmospheres. Atmospheric Environment 35, 3667-3679.

Heal, M.R., Kumar, P., Harrison, R.M. (2012). Particles, Air Quality, Policy and Health. Chemical Society Reviews 41, 6606-6630.

Hinds, W.C. (1999). Aerosol technology: properties, behaviour and measurement of airborne particles. Second ed. John Wiley \& Sons, USA. pp. 483.

Holguín, F., Téllez-Rojo, M.M., Hernández, M., Cortez, M., Chow, J.C., Watson, J.G., Mannino, D., Romieu, I. (2003). Air pollution and heart rate variability among the elderly in Mexico City. Epidemiology 14, 521-527.

IBGE (2000). Instituto Brasileiro de Geografia, Estatística. (Brazilian Institute of Geography and Statistics). Departamento de População, \& Indicadores Sociais. Perfil dos idosos responsáveis pelos domicílios no Brasil, 2000. Available from: http://www.ibge.gov.br/home/estatistica/populacao/perfilidoso/perfidosos2000.pdf (accessed 15 September 2016).

IBGE (2004). Instituto Brasileiro de Geografia e Estatística. (Brazilian Institute of Geography and Statistics). Available from: http://www.ibge.gov.br/home/presidencia/noticias/notasaopaulo.shtm (accessed 05 September 2016).

IBGE (2016). Instituto Brasileiro de Geografia e Estatística. (Brazilian Institute of Geography and Statistics). http://cod.ibge.gov.br/QHF (accessed 28 June 2016). 
Jones, N.C., Thornton, C.A., Mark, D., Harrison, R.M. (2000). Indoor/outdoor relationships of particulate matter in domestic homes with roadside, urban and rural locations. Atmospheric Environment 34, 2603-2612. 
Kampa, M., Castanas, E. (2008). Human health effects of air pollution. Environmental Pollution 151, 362-367.

Kaufman, L. and Rousseeuw, P.J. (1990). Finding Groups in Data: An Introduction to Cluster Analysis. Wiley, New York. ISBN: 0471735787. pp. 342

Klepeis, N.E., Nelson, W.C., Ott, W.R., Robinson, J.P., Tsang, A.M., Switzer, P., Behar, J.V., Hern, S.C., Engelmann, W.H. (2001). The National Human Activity Pattern Survey (NHAPS): a resource for assessing exposure to environmental pollutants. Journal of Exposure Analysis and Environmental Epidemiology 11, 231-252.

Kumar, P., Ketzel, M., Vardoulakis, S., Pirjola, L., Britter, R. (2011). Dynamics and dispersion modelling of nanoparticles from road traffic in the urban atmospheric environment - a review. Journal of Aerosol Science 42, 580-603.

Kumar, P., Morawska, L. (2013). Energy-pollution nexus for urban buildings. Environmental Science \& Technology 47, 7591-7592.

Kumar, P., Khare, M., Harrison, R.M., Bloss, W.J., Lewis, A., Coe, H., Morawska, L., 2015. New Directions: Air pollution challenges for developing megacities like Delhi. Atmospheric Environment 122, 657-661.

Kumar, P., Morawska, L., Birmili, W., Paasonen, P., Hu, M., Kulmala, M., Harrison, R.M., Norford, L., Britter, R. (2014). Ultrafine particles in cities. Environment International $66,1-10$.

Kumar, P., Andrade, M.F., Ynoue, R.Y., Fornaro, A., Freitas, E.D., Martins J., Martins, L.D., Albuquerque, T., Zhang, Y., Morawska, L. (2016) New Directions: From biofuels to wood stoves: the modern and ancient air quality challenges in the megacity of São Paulo. Atmospheric Environment 140, 364-369.

Kumar, P., Goel, A. (2016). Understanding concentration dynamics of coarse and fine particulate matter at and around the signalised traffic intersections. Environmental Science: Process \& Impacts, In Press, doi: 10.1039/C6EM00215C.

Lianou, M., Chalbot, M.C., Kotronarou, A., Kavouras, I.G., Karakatsani, A., Katsouyanni, K., Puustinnen, A., Hameri, K., Vallius, M., Pekkanen, J., Meddings, C., Harrison, R.M., 
Thomas, S., Ayres., J.G., Brink, H., Kos, G., Meliefste, K., Hartog, J.J., Hoek, G. (2007). Dependence of home outdoor particulate mass and number concentrations on residential and traffic features in urban areas. Journal of the Air \& Waste Management Association 57, 1507-1517.

Liao, D., Creason, J., Shy, C., Williams, R., Watts, R., Zweidinger, R. (1999). Daily variation of particulate air pollution and poor cardiac autonomic control in the elderly. Environmental Health Perspectives 107, 521.

Liebmann, B., Jones, C., de Carvalho, L.M. (2001). Interannual variability of daily extreme precipitation events in the state of Sao Paulo, Brazil. Journal of Climate 14, 208-218.

Maimon, O., Rokach, L. (2010). Data mining and knowledge discovery handbook. New York: Springer. Second ed. ISBN: 9780387098227. pp. 1269.

Martins, L.D., Martins, J.A., Freitas, E.D., Mazzoli, C.R., Gonçalves, F.L.T., Ynoue, R.Y., Hallak, R., Albuquerque., T.T.A., Andrade, M.F. (2010). Potential health impact of ultrafine particles under clean and polluted urban atmospheric conditions: a modelbased study. Air Quality, Atmosphere \& Health 3, 29-39.

Mehta, A. J., Zanobetti, A., Bind, M.C., Kloog, I., Koutrakis, P., Sparrow, D., Vokonas, P.S., Schwartz, J.D. (2016). Long-term exposure to ambient fine particulate matter and renal function in older men: the VA normative aging study. Environmental Health Perspectives, In press, doi: 10.1289/ehp.1510269.

Miranda, R.M., Andrade, M.F., Fornaro, A., Astolfo, R., Andre, P.A., Saldiva, P. (2012). Urban air pollution: a representative survey of $\mathrm{PM}_{2.5}$ mass concentrations in six Brazilian cities. Air quality, Atmosphere \& Health 5, 63-77.

Misra, C., Singh, M., Shen, S., Sioutas, C., Hall, P.M. (2002). Development and evaluation of a personal cascade impactor sampler (PCIS). Journal of Aerosol Science 33, 1027-1047.

McCormack, M.C., Breysse, P.N., Hansel, N.N., Matsui, E.C., Tonorezos, E.S., CurtinBrosnan, J., Williams, D.L., Buckley, T.J., Eggleston, P.A., Diette, G.B. (2008). Common household activities are associated with elevated particulate matter concentrations in bedrooms of inner-city Baltimore pre-school children. Environmental Research 106, 148-155. 
Nascimento, L.F.C. (2011). Air pollution and cardiovascular hospital admissions in a medium-sized city in São Paulo State, Brazil. Brazilian Journal of Medical and Biological Research 44, 720-724.

Olmo, N.R.S., Saldiva, P.H.D.N., Braga, A.L.F., Lin, C.A., Santos, U.D.P., Pereira, L.A.A. (2011). A review of low-level air pollution and adverse effects on human health: implications for epidemiological studies and public policy. Clinics 66, 681-690.

Osman, L.M.; Douglas, J.G.; Garden, C.; Reglitz, K.; Lyon, J.; Gordon, S.; Ayres, J.G. (2007) Indoor air quality in homes of patients with chronic obstructive pulmonary disease. American Journal of Respiratory and Critical Care Medicine 176, 465-472.

Padhi, B.K., Adhikari, A., Satapathy, P., Patra, A.K., Chandel, D., Panigrahi, P. (2016). Predictors and respiratory depositions of airborne endotoxin in homes using biomass fuels and LPG gas for cooking. Journal of Exposure Science and Environmental Epidemiology, In press, doi: 10.1038/jes.2016.5.

Peled, R. (2011). Air pollution exposure: Who is at high risk?. Atmospheric Environment 45 $1781-1785$.

Pinheiro, S.D.L.L.D., Saldiva, P.H.N., Schwartz, J., Zanobetti, A. (2014). Isolated and synergistic effects of $\mathrm{PM}_{10}$ and average temperature on cardiovascular and respiratory mortality. Revista de Saúde Pública 48, 881-888.

Pope III, C.A. (2000). Epidemiology of fine particulate air pollution and human health: biologic mechanisms and who's at risk?. Environmental Health Perspectives 108, 713 723.

Power, M.C., Weisskopf, M.G., Alexeeff, S.E., Coull, B.A., Spiro III, A., Schwartz, J. (2011). Traffic-related air pollution and cognitive function in a cohort of older men. Environmental Health Perspectives 119, 682-687.

Quiroga, O. L. L. (2007). O Garmic e a luta por moradia para idosos na cidade de São Paulo. Kairós Gerontologia. Revista da Faculdade de Ciências Humanas e Saúde. ISSN 2176$901 X$

Saldiva, P.H., Pope III, C.A., Schwartz, J., Dockery, D.W., Lichtenfels, A.J., Salge, J.M., 
Barone, I., Bohm, G.M. (1995). Air pollution and mortality in elderly people: a timeseries study in Sao Paulo, Brazil. Archives of Environmental Health: An International Journal 50, 159-163.

Salthammer T., Uhde, E., Schripp, T., Schieweck, A., Morawska, L., Mazaheri, M., Clifford, S., He, C., Buonanno, G., Querol, X., Kumar, P. (2016). Children's well-being at schools: Impact of climatic conditions and air pollution. Environment International 94, 196-210.

Sánchez-Ccoyllo, O.R., Fatima Andrade, M. (2002). The influence of meteorological conditions on the behavior of pollutants concentrations in São Paulo, Brazil. Environmental Pollution. 116, 257-263.

Segalin, B., Gonçalves, F.L.T., Fornaro, A. (2016). Black Carbon em material particulado nas residências de idosos na Região Metropolitana de São Paulo, Brasil. Revista Brasileira de Meteorologia 31, 311-318, doi: 10.1590/0102-778631320150145.

Seinfeld, J.H., Pandis, S.N. (2016). Atmospheric chemistry and physics: from air pollution to climate change. Third ed. John Wiley \& Sons. USA. pp. 1152.

Simoni, M., Jaakkola, M.S., Carrozzi, L., Baldacci, S., Di Pede, F., Viegi, G. (2003). Indoor air pollution and respiratory health in the elderly. European Respiratory Journal 21, 15 20 .

Sioutas, C. (2004). Development of New Generation Personal Monitors for Fine Particulate Matter (PM) and its Metal Content. Mickey Leland National Urban Air Toxics Research Center. pp. 29.

Singh, M., Misra, C., Sioutas, C. (2003). Field evaluation of a personal cascade impactor sampler (PCIS). Atmospheric Environment 37, 4781-4793.

Weuve, J., Puett, R.C., Schwartz, J., Yanosky, J.D., Laden, F., Grodstein, F. (2012). Exposure to particulate air pollution and cognitive decline in older women. Archives of Internal Medicine 172, 219-227.

WHO (2006). World Health Organization, Regional Office for Europe. Air quality guidelines: global update 2005: particulate matter, ozone, nitrogen dioxide, and sulfur dioxide. 
ISBN: 9289021926. pp. 484.

WHO (2010). World Health Organization, Regional Office for Europe. WHO Guidelines for indoor air quality: selected pollutants. ISBN: 9789289002134 . pp. 484.

Wilks, D.S. (1995) Statistical methods in the atmospheric sciences, Second edition. International Geophysics Series, Academic Press 59. pp. 464.

Wilson, W.E., Suh, H.H. (1997). Fine particles and coarse particles: concentration relationships relevant to epidemiologic studies. Journal of the Air \& Waste Management Association. 47, 1238-1249.

United Nations (2015). World Population Prospects: The 2015 Revision, Key Findings and Advance Tables. United Nations, Department of Economic and Social Affairs, Population Division. $\quad$ ESA/P/WP.241. $\quad$ pp. https://esa.un.org/unpd/wpp/Publications/Files/Key_Findings_WPP_2015.pdf (accessed 10 May 2016).

Viana, M., Rivas, I., Querol, X., Alastuey, A., Sunyer, J., Álvarez-Pedrerol, M., Buoso, L., Sioutas, C. (2014). Indoor/outdoor relationships and mass closure of quasi-ultrafine, accumulation and coarse particles in Barcelona schools. Atmospheric Chemistry and Physics 14, 4459-4472. 


\section{List of Figures}

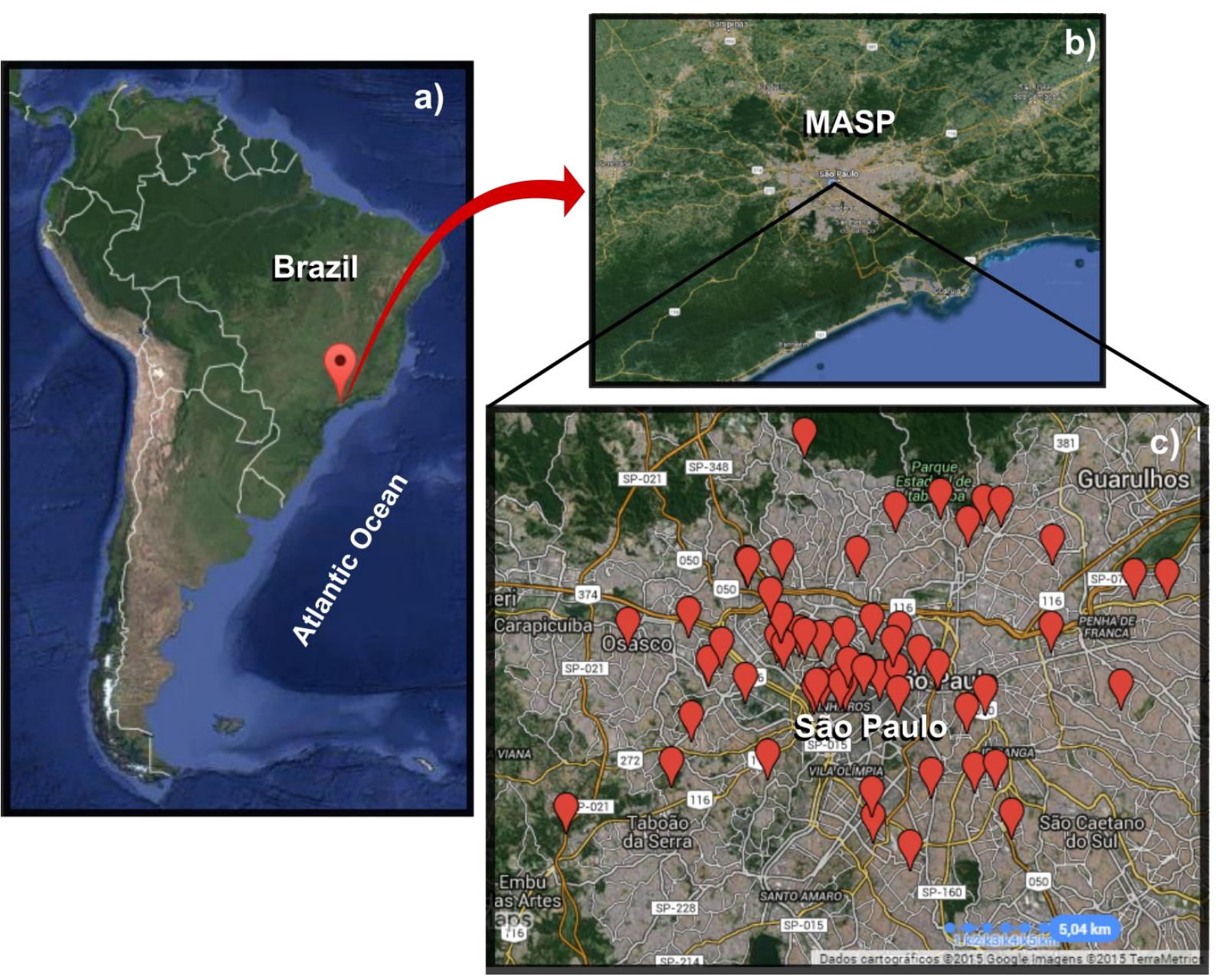

Figure 1. Maps of (a) Brazil in South America, (b) Metropolitan Area of São Paulo - MASP, and (c) locations of elderly residences where indoor PM size-resolved were sampled in MASP. The pictures were taken from Google maps (https://maps.google.com/). 

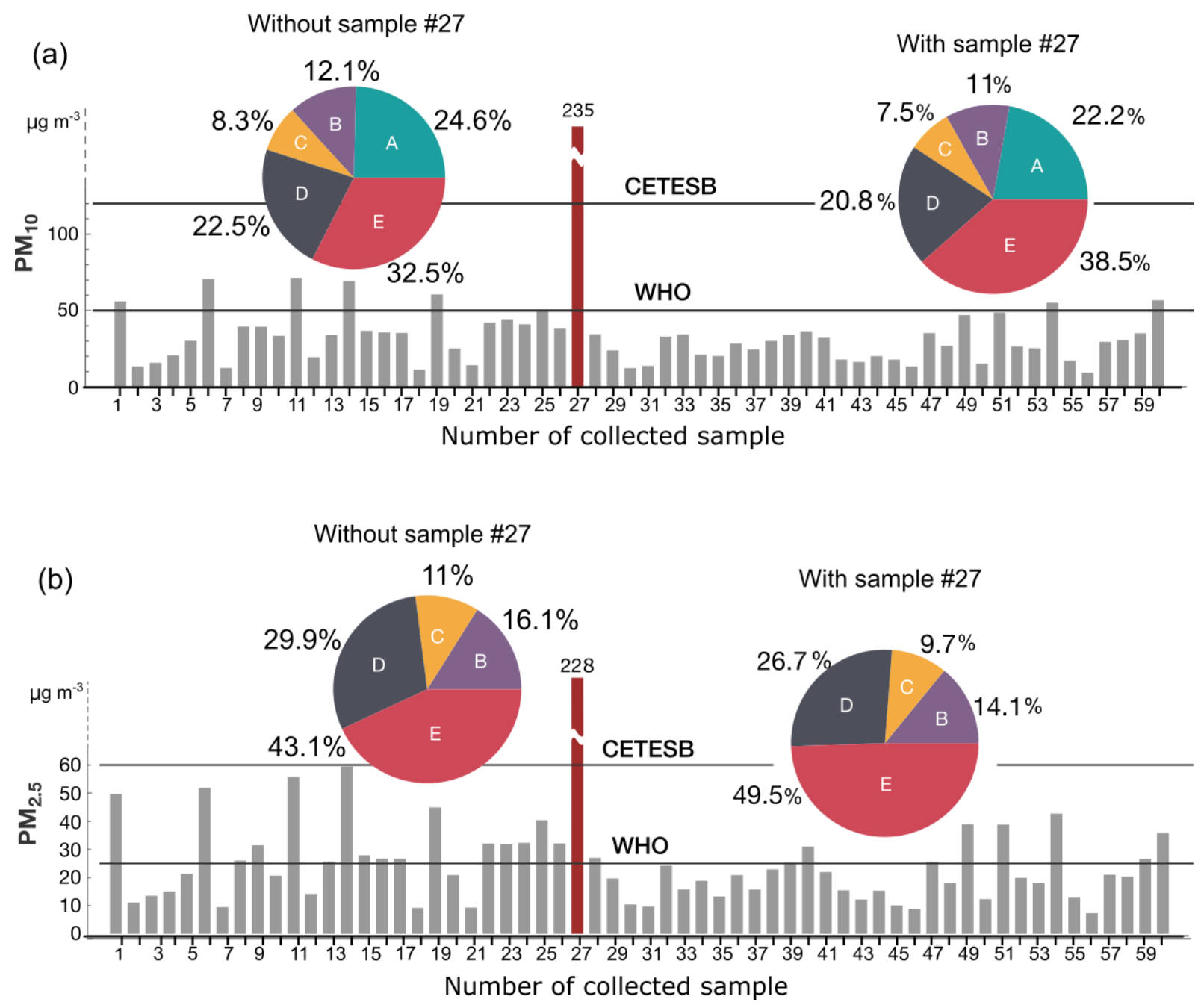

Figure 2. Mass concentrations of (a) $\mathrm{PM}_{10}$ and (b) $\mathrm{PM}_{2.5}$ in elderly residences, sampling performed for 24 hours with PCIS. The lines represent the São Paulo State air quality standards (CETESB) and the WHO guidelines. The red columns show the highest $\mathrm{PM}_{10}$ and $\mathrm{PM}_{2.5}$ concentrations in the sample \#27, discussed in Section 3.1. The pie chart represents the percentage of each PCIS stage: A, B, C, D and E, corresponding $\mathrm{PM}_{2.5-10}, \mathrm{PM}_{1.0-2.5}, \mathrm{PM}_{0.5-1.0}$, $\mathrm{PM}_{0.25-0.5}$ and $\mathrm{PM}_{<0.25}$, respectively, and including the sample \#27 only on the left side. 
(a)

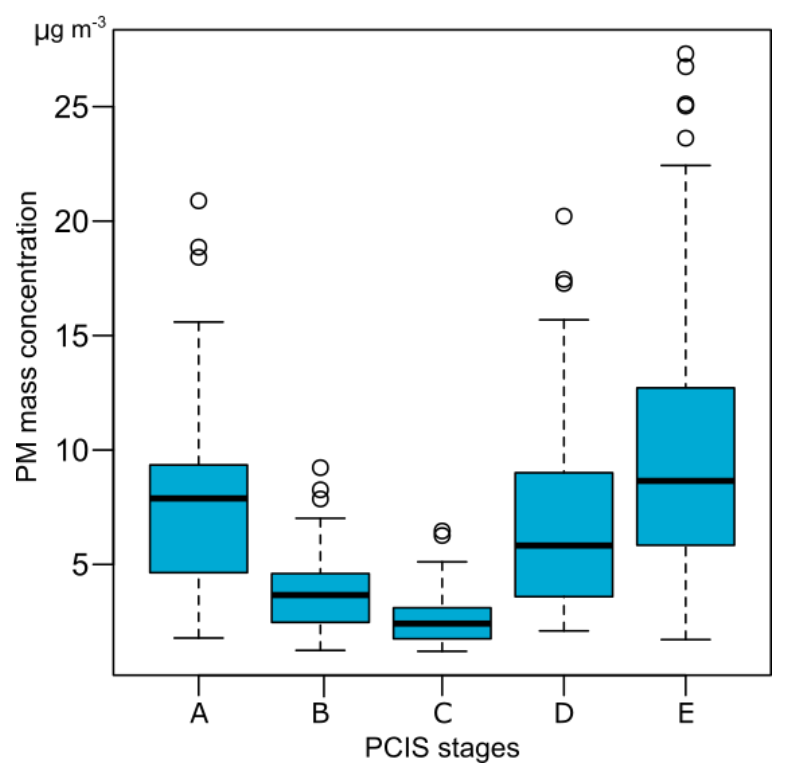

(b)

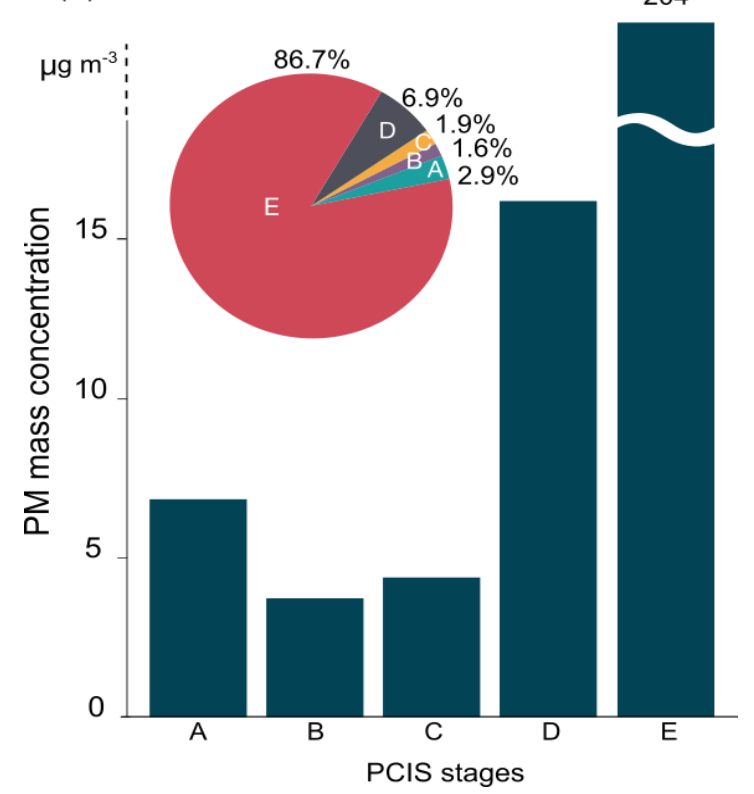

Figure 3. Size-resolved particle mass concentrations (a) for the entire sample sets, except the

(b) sample \#27 that showed the highest concentrations of $\mathrm{PM}_{<0.25}$ discussed in Section 3.1. A,

$\mathrm{B}, \mathrm{C}, \mathrm{D}$ and $\mathrm{E}$ are $\mathrm{PM}_{2.5-10}, \mathrm{PM}_{1.0-2.5}, \mathrm{PM}_{0.5-1.0}, \mathrm{PM}_{0.25-0.5}$ and $\mathrm{PM}_{<0.25}$, respectively. 


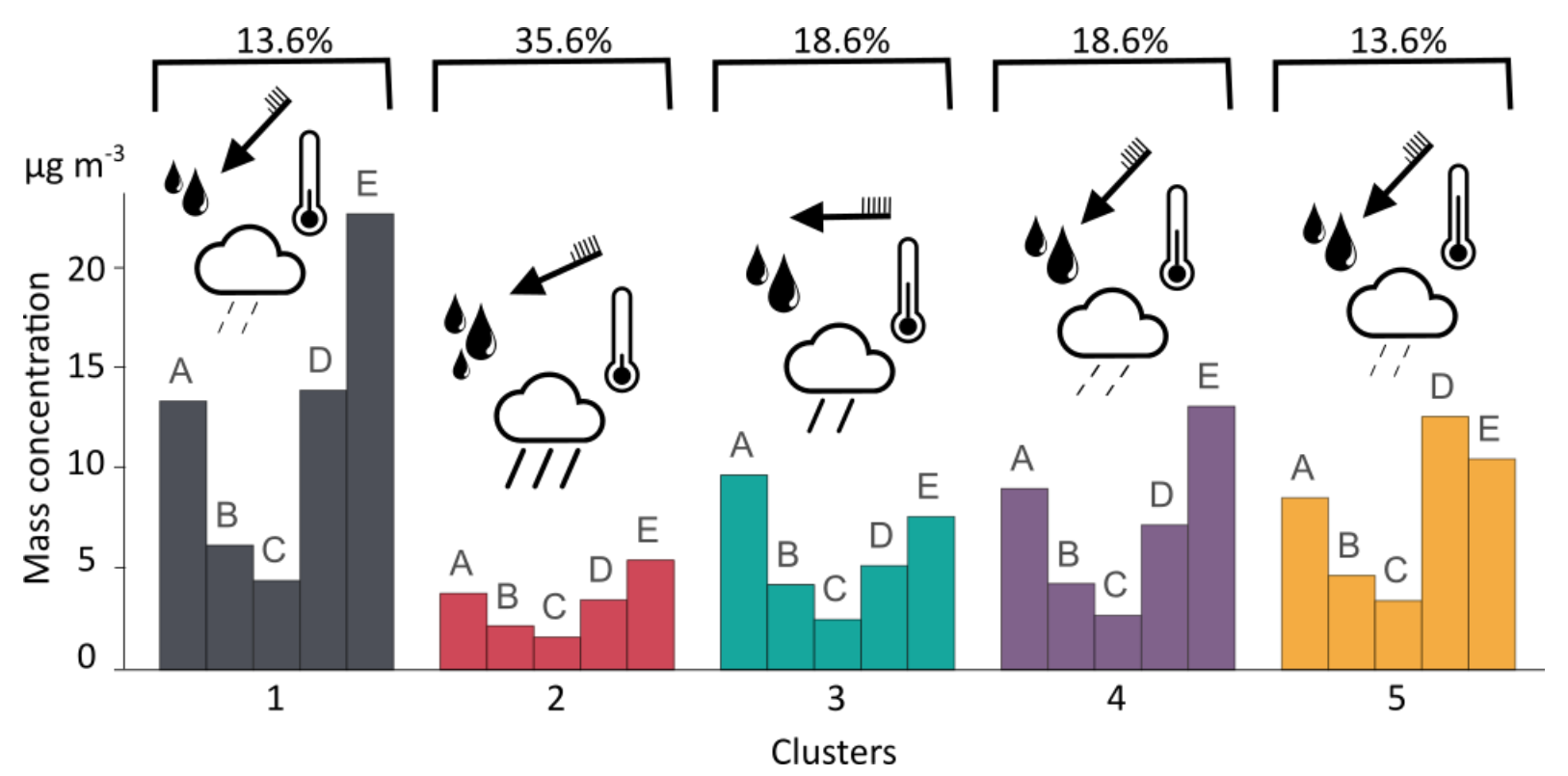

Figure 4: Clusters of the elderly residences. The brackets represent the percentage of residences in each cluster. $\mathrm{A}, \mathrm{B}, \mathrm{C}, \mathrm{D}$ and $\mathrm{E}$ are $\mathrm{PM}_{2.5-10}, \mathrm{PM}_{1.0-2.5}, \mathrm{PM}_{0.5-1.0}, \mathrm{PM}_{0.25-0.5}$ and $\mathrm{PM}_{<0.25}$, respectively. The cloud, thermometer, rain drops, and the arrow represent the precipitation, temperature, relative humidity, and wind direction and speed, respectively. The interpretation of these qualitative symbols can be seen in Table 3. 

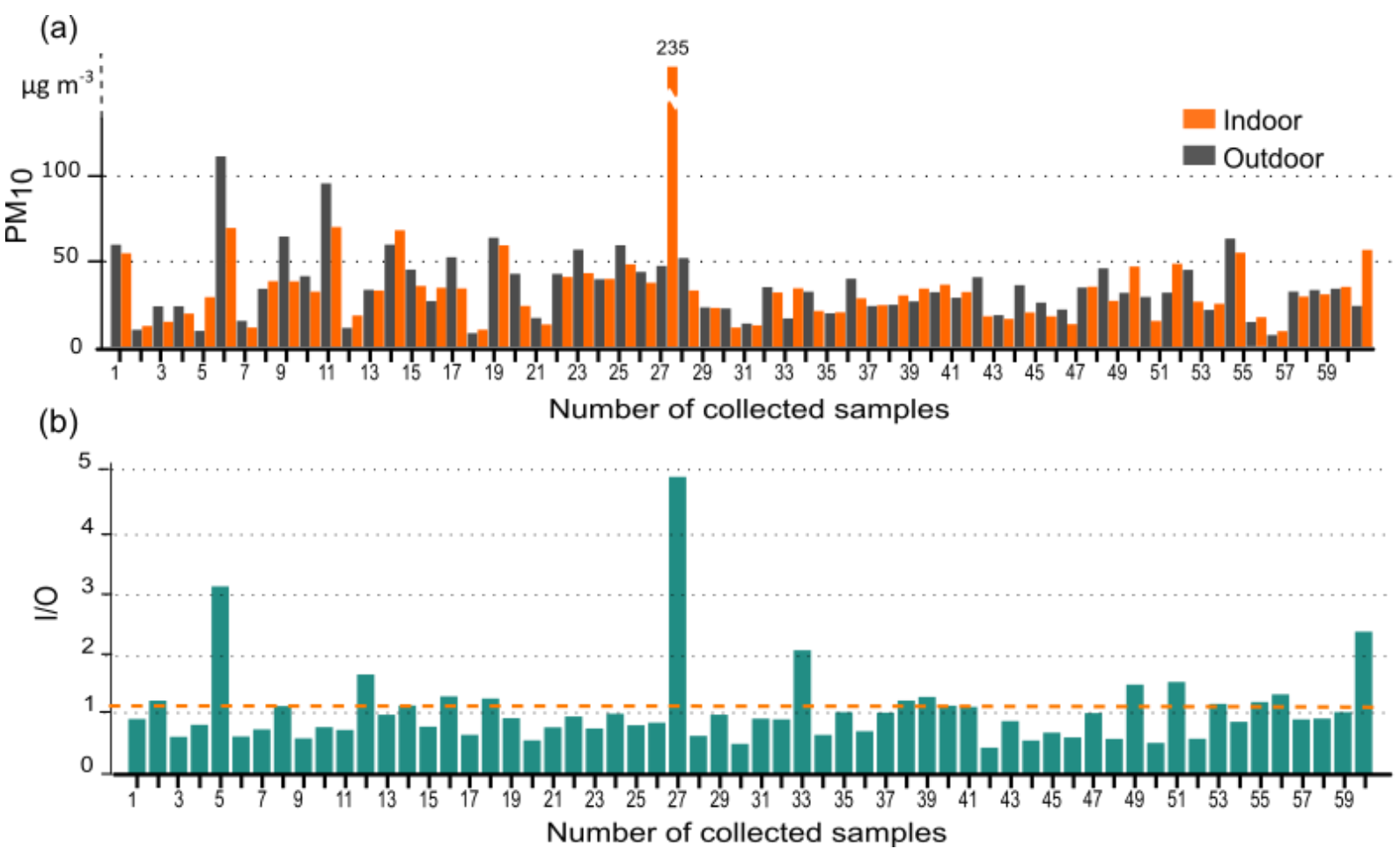

Figure 5. $\mathrm{PM}_{10}$ mass concentration ( $\mathrm{a}$ - indoor) in elderly residences and (a - outdoor) in its valid outdoor air quality stations (CETESB) and (b) $\mathrm{PM}_{10}$ indoor/outdoor rates $(I / O)$. The dashed line represents the mean $I / O$. 


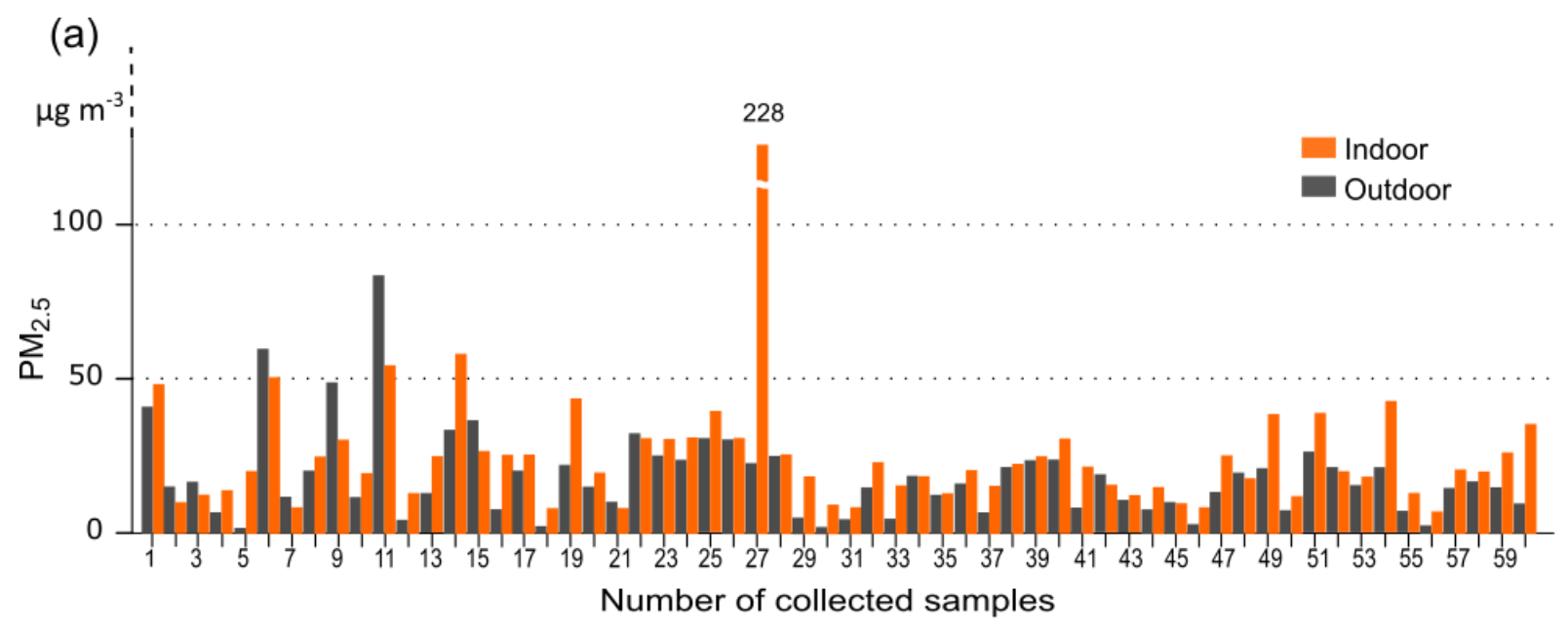

(b)

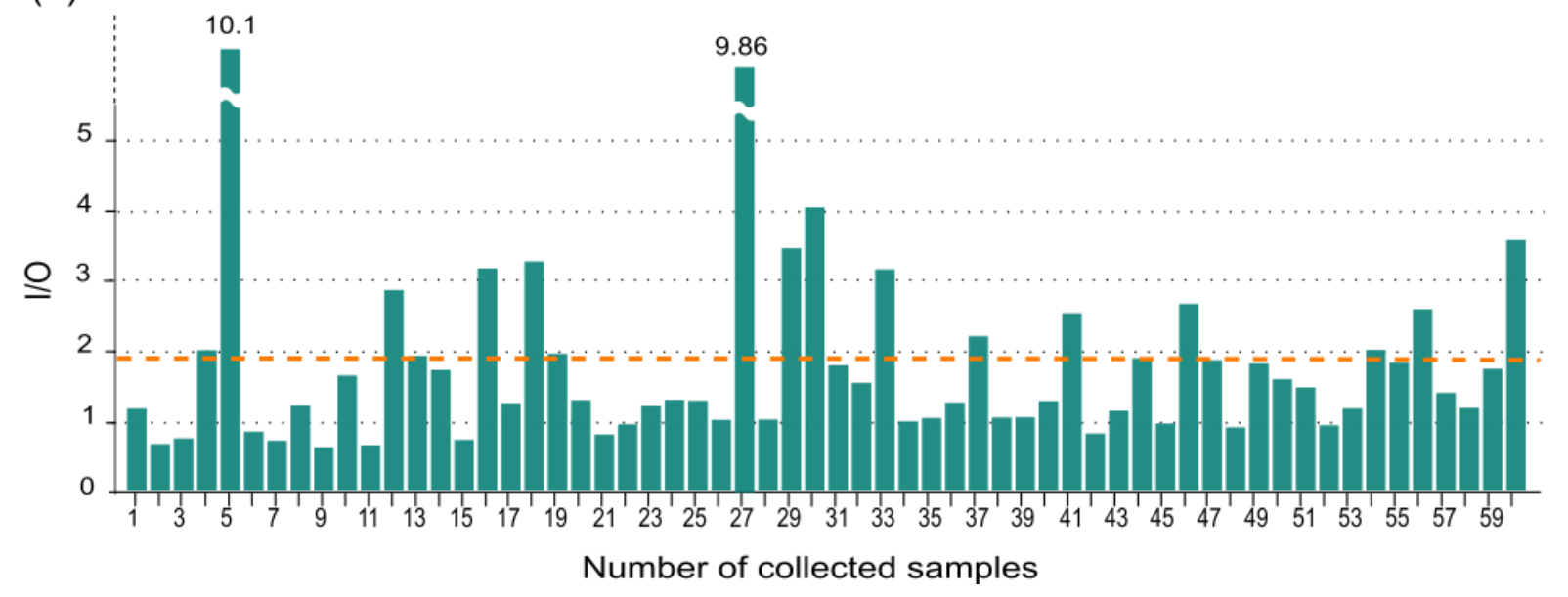

Figure 6. $\mathrm{PM}_{2.5}$ mass concentration ( $\mathrm{a}$ - indoor) in elderly residences and ( $\mathrm{a}$ - outdoor) in its valid outdoor air quality stations $(\mathrm{CETESB})$ and (b) $\mathrm{PM}_{2.5}$ indoor/outdoor rates $(I / O)$. The dashed line represents the mean $I / O$. 


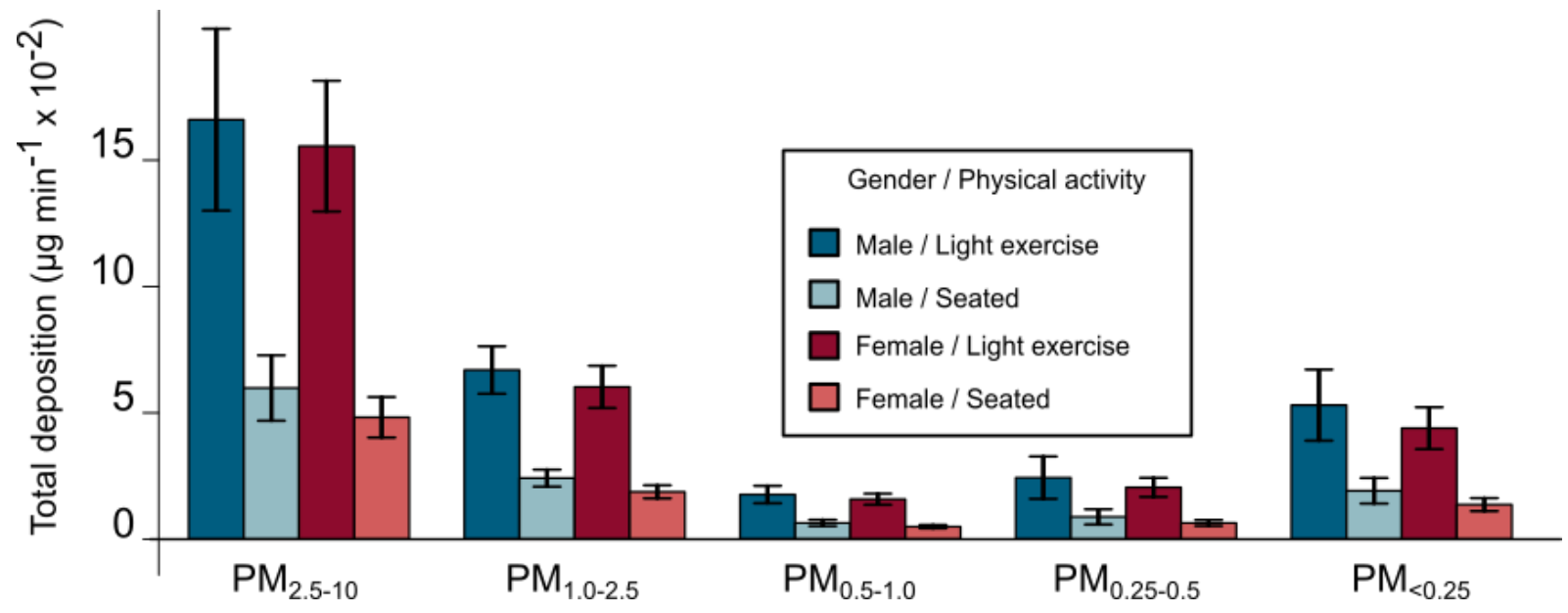

Figure 7. Respiratory deposition doses (RDD) throughout the respiratory tract of elderly male and female subjects during sitting and light exercises positions for size-resolved particles, without the sample \#27. 


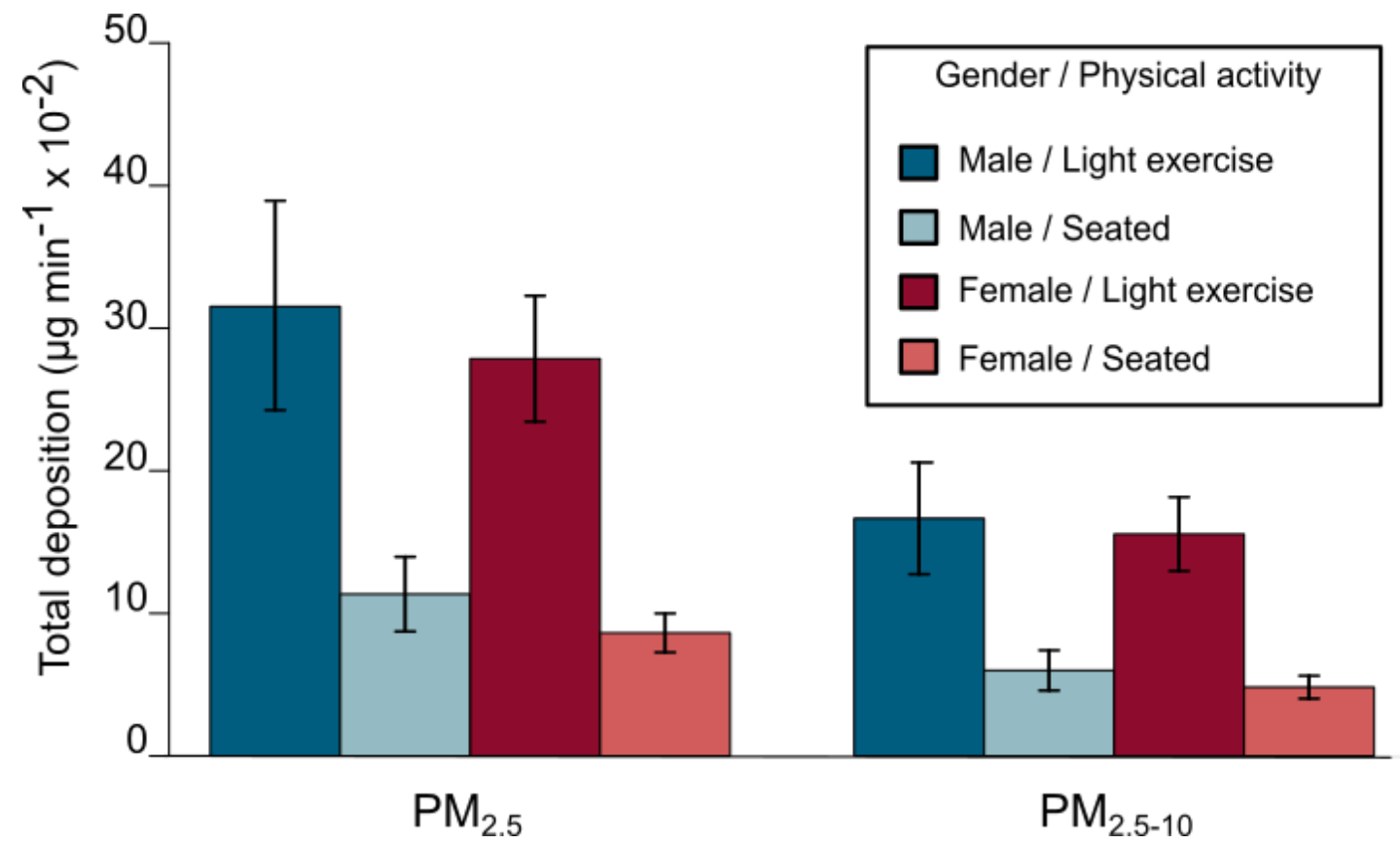

Figure 8. Respiratory deposition doses (RDD) throughout the respiratory tract of elderly male and female subjects during sitting and light exercises positions for fine $\left(\mathrm{PM}_{2.5}\right)$ and coarse $\left(\mathrm{PM}_{2.5-10}\right)$ particles, without the sample \#27. 


\section{List of Tables}

Table 1. Review of past relevant studies including indoor PM in different size ranges.

\begin{tabular}{|c|c|c|c|}
\hline Range & $\begin{array}{l}\text { Environment } \\
\text { type }\end{array}$ & Key conclusion & Source \\
\hline $\begin{array}{l}\mathrm{PM}_{10}, \mathrm{PM}_{2.5} \\
\mathrm{PM}_{<1.0}\end{array}$ & $\begin{array}{l}\text { Urban, rural } \\
\text { and roadside } \\
\text { residences }\end{array}$ & $\begin{array}{l}\text { - I/O ratios were greater for fine than coarse } \\
\text { particles, and for roadside residences }\end{array}$ & $\begin{array}{l}\text { Jones et } \\
\text { al. (2000) }\end{array}$ \\
\hline $\mathrm{PM}_{10}, \mathrm{PM}_{2.5}$ & $\begin{array}{l}\text { Urban } \\
\text { residences }\end{array}$ & $\begin{array}{l}\text { - } \mathrm{I} / O \text { ratios were greater for } \mathrm{PM}_{2.5} \text { than } \mathrm{PM}_{10} \text {; } \\
\text { - Residences close to heavy traffic have more } \\
\mathrm{PM} \text { mass concentration. }\end{array}$ & $\begin{array}{l}\text { Chao and } \\
\text { Wong } \\
\text { (2002) }\end{array}$ \\
\hline $\mathrm{PM}_{10}, \mathrm{PM}_{2.5}$ & $\begin{array}{l}\text { Children } \\
\text { urban } \\
\text { residences }\end{array}$ & $\begin{array}{l}\text { - } \mathrm{PM}_{2.5} \text { and } \mathrm{PM}_{10} \text { have mean } 39.5 \pm 34.5 \text { and } \\
56.2 \pm 44.8 \mu \mathrm{g} \mathrm{m}^{-3} \text {, respectively } \\
\text { - Open windows were associated with } \\
\text { significantly lower indoor PM }\end{array}$ & $\begin{array}{l}\text { McCorma } \\
\text { ck et al. } \\
(2008)\end{array}$ \\
\hline $\begin{array}{l}\mathrm{PM}_{10}, \mathrm{PM}_{2.5} \\
\mathrm{PM}_{<1.0}\end{array}$ & $\begin{array}{l}\text { Commercial } \\
\text { building }\end{array}$ & $\begin{array}{l}\text { - } \mathrm{PM}_{10} \text { and } \mathrm{PM}_{2.5} \text { indoor exceed the national } \\
\text { standard } \\
\text { - } I / O \text { is bigger for naturally ventilated places } \\
(>1)\end{array}$ & $\begin{array}{l}\text { Goyal and } \\
\text { Kumar } \\
\text { (2013) }\end{array}$ \\
\hline $\begin{array}{l}\mathrm{PM}_{2.5-10,}, \mathrm{PM}_{0.25-} \\
2.5, \mathrm{PM}_{<0.25}\end{array}$ & School & $\begin{array}{l}\text { - } I / O \text { ratios }>1 \text { if indoor sources influence is } \\
\text { greater than outdoor sources; a ratio of }<1 \\
\text { indicates the other way around; } \\
\text { - } \mathrm{PM}_{<0.25} \text { indoor has mean } 23.4 \mu \mathrm{g} \mathrm{m}^{-3}\end{array}$ & $\begin{array}{l}\text { Viana et } \\
\text { al. (2014) }\end{array}$ \\
\hline $\mathrm{PM}_{2.5} ; \mathrm{PM}_{<0.25}$ & $\begin{array}{l}\text { Elderly urban } \\
\text { residences }\end{array}$ & $\begin{array}{l}\text { - Almost half of } \mathrm{PM}_{2.5} \text { is } \mathrm{PM}_{<0.25} \\
\text { - } 26 \% \text { of } \mathrm{PM}_{<0.25} \text { is composed by Black Carbon } \\
\text { (measured by reflectance) }\end{array}$ & $\begin{array}{l}\text { Segalin et } \\
\text { al. (2016) }\end{array}$ \\
\hline $\begin{array}{l}\mathrm{PM}_{10}, \mathrm{PM}_{2.5} \\
\mathrm{PM}_{2.5-10}, \mathrm{PM}_{1.0-} \\
2.5, \mathrm{PM}_{0.5-1.0} \\
\mathrm{PM}_{0.25-0.5} \\
\mathrm{PM}_{<0.25}\end{array}$ & $\begin{array}{l}\text { Elderly urban } \\
\text { residences }\end{array}$ & $\begin{array}{l}\text { - } I / O \text { ratios were greater for } \mathrm{PM}_{2.5} \text { than } \mathrm{PM}_{10} \text {; } \\
\text { both have a ratio }>1 \\
\text { - Indoor } \mathrm{PM}_{10} \text { and } \mathrm{PM}_{2.5} \text { has a mean of } 35.2 \\
\text { and } 27.4 \mu \mathrm{g} \mathrm{m}^{-3} \text {, respectively. }\end{array}$ & This study \\
\hline
\end{tabular}


Table 2. Mean and standard deviation of PM in elderly residences, with and without the sample \#27 (Figure 3b), and residences with or without the smoking during the sampling.

\begin{tabular}{llllll}
\hline PM sizes & $\begin{array}{l}\text { With sample } \\
\# 27\end{array}$ & $\begin{array}{l}\text { Without } \\
\text { sample \#27 }\end{array}$ & $\begin{array}{l}\text { Mean } \\
\text { difference* } \\
(\%)\end{array}$ & $\begin{array}{l}\text { Smoking } \\
\text { residences }\end{array}$ & $\begin{array}{l}\text { No smoking } \\
\text { residences } \\
\text { (no \#27) }\end{array}$ \\
\hline $\mathrm{PM}_{2.5-10}$ & $7.83 \pm 4.25$ & $7.85 \pm 4.29$ & 0.2 & $4.66 \pm 2.73$ & $7.99 \pm 4.42$ \\
\hline $\mathrm{PM}_{1.0-2.5}$ & $3.86 \pm 1.71$ & $3.86 \pm 1.72$ & 0.1 & $2.34 \pm 1.32$ & $3.93 \pm 1.75$ \\
\hline $\mathrm{PM}_{0.5-1.0}$ & $2.66 \pm 1.22$ & $2.63 \pm 1.21$ & 1.1 & $2.01 \pm 0.93$ & $2.6 \pm 1.2$ \\
\hline $\mathrm{PM}_{0.25-0.5}$ & $7.32 \pm 4.59$ & $7.17 \pm 4.48$ & 2.1 & $6.89 \pm 2.30$ & $7.02 \pm 4.41$ \\
\hline $\mathrm{PM}_{<0.25}$ & $13.6 \pm 25.7$ & $10.4 \pm 6.32$ & 23.7 & $11.3 \pm 2.73$ & $10.0 \pm 5.92$ \\
\hline $\mathrm{PM}_{10}$ & $35.2 \pm 37.5$ & $31.9 \pm 18.0$ & 9.6 & $25.5 \pm 12.4$ & $31.6 \pm 17.7$ \\
\hline $\mathrm{PM}_{2.5}$ & $27.4 \pm 29.1$ & $24.0 \pm 12.4$ & 12.4 & $21.4 \pm 8.87$ & $23.6 \pm 12.2$ \\
\hline
\end{tabular}

* Mean difference between samples with and without sample \#27. 
Table 3. Meteorological mean parameters for the clusters in Figure 4. Mean precipitation $(P)$ in all residences for each cluster, percentage of precipitation days $\left(\mathrm{P}_{\text {days }}\right)$, days without the precipitation before the sampling period (days without $\mathrm{P}$ ), relative humidity $(R H)$, wind speed $(U)$ and direction $(W D)$ and temperature air $(T)$ measured in the IAG station - USP, for sampling period with PCIS in the elderly residences.

\begin{tabular}{llllll}
\hline Cluster & $\mathbf{1}$ & $\mathbf{2}$ & $\mathbf{3}$ & $\mathbf{4}$ & $\mathbf{5}$ \\
\hline $\mathrm{P}(\mathrm{mm})$ & 0.62 & 5.0 & 1.4 & 0.14 & 0.68 \\
\hline $\mathrm{P}_{\text {days }}(\%)$ & 25.0 & 86.4 & 54.5 & 27.3 & 25.0 \\
\hline Days without $\mathrm{P}$ & 3.3 & 0.8 & 2.0 & 2.0 & 5.5 \\
\hline$R H(\%)$ & 72.4 & 85.9 & 77.3 & 75.4 & 79.2 \\
\hline$U\left(\mathrm{~m} \mathrm{~s}^{-1}\right)$ & 4.4 & 5.6 & 6.0 & 5.6 & 5.4 \\
\hline$W D$ & $\mathrm{NE}$ & $\mathrm{ENE}$ & $\mathrm{E}$ & $\mathrm{NE}$ & $\mathrm{NE}$ \\
\hline$T\left({ }^{\circ} \mathrm{C}\right)$ & 18.3 & 17.8 & 19.1 & 18.6 & 20.2 \\
\hline
\end{tabular}


Table 4. Mean-difference (\%) in RDD between the male and female elderly while sitting or during light exercises for different PM size stages. The mean-difference value of RDD is calculated considering male elderly RDD as a reference.

\begin{tabular}{lcc}
\hline Ranges & $\begin{array}{c}\text { \% of difference in } \\
\text { RDD during seated }\end{array}$ & $\begin{array}{c}\text { \% of difference in RDD during } \\
\text { light exercise }\end{array}$ \\
\hline $\mathrm{PM}_{2.5-10}$ & 19.6 & 6.6 \\
\hline $\mathrm{PM}_{1.0-2.5}$ & 22.4 & 9.8 \\
\hline $\mathrm{PM}_{0.5-1.0}$ & 18.0 & 4.7 \\
\hline $\mathrm{PM}_{0.25-0.5}$ & 19.3 & 6.2 \\
\hline $\mathrm{PM}_{<0.25}$ & 28.8 & 17.2 \\
\hline $\mathrm{PM}_{2.5-10}$ & 20.0 & 6.0 \\
\hline $\mathrm{PM}_{2.5}$ & 24.6 & 11.4 \\
\hline
\end{tabular}

